\title{
Study of the Transient Operation of Low Heat Rejection Turbocharged Diesel Engine Including Wall Temperature Oscillations
}

\author{
Constantine D. Rakopoulos and Evangelos G. Giakoumis \\ School of Mechanical Engineering, National Technical University of Athens
}

Copyright @ 2007 SAE International

\begin{abstract}
During the last decades, a vivid interest in the low heat rejection (LHR) diesel engine has arisen. In a LHR engine, an increased level of temperatures inside the cylinder is achieved resulting from the insulation applied to the combustion chamber walls. The steady-state LHR engine operation has been studied so far by applying either first- or second-law balances. However, very few works have treated this subject during the very important transient operation, with the results limited to the engine speed response. For this purpose, an experimentally validated simulation code of the thermodynamic cycle of the engine during transient conditions is applied. This takes into account the transient operation of the fuel pump, the development of friction torque using a detailed per degree crank angle sub-model, while the equations for each cylinder are solved individually and sequentially. In this work, two common insulators of various thicknesses are considered for the engine in hand, viz. silicon nitride and plasma spray zirconia. The transient response of various engine (e.g. speed, volumetric efficiency, fuel pump rack position, brake mean effective pressure and specific fuel consumption) and turbocharger variables is depicted and analyzed, with the results compared to the non-insulated transientand the insulated steady-state operation. For a more indepth analysis of transient engine heat transfer, the interesting phenomenon of the short-term temperature (cyclic) oscillations in the combustion chamber walls during transients needs to be studied. To this aim, the thermodynamic model of the engine is appropriately coupled to a wall periodic heat conduction model, which uses the gas temperature variation as boundary condition throughout the engine cycle after being treated by Fourier analysis techniques. The evolution of many variables during the transient engine cycles, such as the amplitude of oscillation or gradient of temperature swing is thus illustrated. Moreover, the simulation code is expanded in a way to include the second-law balance, as this may prove an interesting alternative to the firstlaw analysis. It is revealed that after a ramp increase in load, the second-law values unlike the first-law ones are heavily impacted by the insulation scheme applied.
\end{abstract}

Combustion and total engine irreversibilities decrease significantly (up to $24 \%$ for the cases examined) with increasing insulation. Unfortunately, this decrease is not transformed into an increase in piston work but rather increases the potential for extra work recovery owing to the higher availability content of the exhaust gas.

\section{INTRODUCTION}

The importance of heat transfer to the combustion chamber walls of internal combustion engines has been recognized from the early stages of their development. Results from various theoretical and experimental research efforts on the subject have been well documented in the literature during the last decades, e.g. [1-5]. In recent years, the interest for the heat transfer phenomena in internal combustion engines has been greatly intensified because of their major importance, among other things, on the thermal loading at critical places in the combustion chamber components. Heat transfer in internal combustion engines is extremely complex, since the relevant phenomena are of transient nature even under steadystate engine operation, three-dimensional, and subject to rapid variations in cylinder gas pressure and temperatures during an engine cycle.

Moreover, during the last two decades, there has been an increasing interest in the low heat rejection (LHR, or sometimes loosely termed "adiabatic") diesel engine $[2,3,6-8]$. The objective of a low heat rejection cylinder is to minimize heat loss to the walls, eliminating the need for a cooling system. This is achieved through the increased level of (wall) temperatures resulting from the insulation applied to the cylinder walls, piston crown, cylinder head, or valves. By so doing, a reduction can be observed in ignition delay and thus combustion noise, and also in hydrocarbon and particulate matter emissions. At the same time an increase in exhaust gas energy is observed; the latter can be recovered using some kind of bottoming device, e.g. in the form of a Rankine cycle or a turbo-compound configuration. A major issue here is the decrease in the volumetric efficiency, which affects adversely the power output, and 
the increase in NOx emissions [3]. Deterioration of combustion as well as of the lubricating oil properties have been also reported resulting from the increased levels of insulation. Consequently, some researchers have proposed the use of thin coatings for best results $[9,10]$. As regards steady-state operation, various studies have been reported for LHR engine operation by applying either first-, e.g. [2,6-11], or second-law, e.g. [12-16] balances.

However, it is a well-known fact today that transient turbocharged diesel engine operation is of particular importance since it is often linked with off-design, e.g. turbocharger lag, and consequently non-optimum performance, leading to unacceptable exhaust emissions and poor speed response [17-20]. During the last decades diesel engine modeling and experimental investigation has offered great help towards the study and optimisation of transient operation; however, the number of works committed so far to the study of the LHR diesel engine when operating under transient conditions is extremely narrow, with the results limited to the engine speed response [17,21-23].

Past reserach has highlighted an important aspect of engine heat transfer, namely the (transient) temperature and heat flux variations in the combustion chamber walls. These can be divided into two main categories:

- The long-term response ones, resulting from the large time scale (of the order of seconds), nonperiodic variations of engine speed and/or load, and

- The short-term response ones, which are the result of the fluctuations of gas pressure and temperature during an engine cycle, having a time period of the order of ms.

The development of the long-term temperature variations after a load or speed change was studied by Keribar and Morel [22], who simulated in detail the heat transfer process separately for the piston crown, cylinder liner, cylinder head and valves. Keribar and Morel as well as Rakopoulos et al. [24,25] applied finite element methods to the structure of the cylinder walls and identified the fact that the thermal shock, i.e. the sharp temperature gradients development in the engine structure after a ramp increase in load or fueling, may take prohibitive values impairing the engine performance. This is due to the high wall thermal fatigue when thermal insulators are used.

Unlike their long-term counterparts, the short-term temperature variations develop fully during each engine cycle. They can assume increased values during a transient event after a ramp increase in load, since fueling and hence gas temperatures increase significantly in only a few seconds. Assanis and Heywood [2] studied the development of the short-term response temperature variations in engine cylinder walls that were partially insulated with plasma spray zirconia (PSZ). They applied a single-zone model on a turbocharged and turbo-compound diesel engine, and highlighted the increased magnitude (of the order of more than $100 \mathrm{~K}$ ) of the developed temperature oscillations during a steady-state engine cycle. Wong et al. [10] investigated the interdependence between engine efficiency and temperature swings amplitude. Rakopoulos et al. [26,27] focused on a naturally aspirated diesel engine and included the effect of silicon nitride insulation, providing comparative results for the various insulation schemes applied. Yamada et al. [28] expanded the temperature swings analysis to cover even the case where the deposit on the cylinder wall affects the gas-to-cylinder heat transfer.

Some researchers, [e.g. 28-31] have studied experimentally the short-term temperature variations and commented on the high complexity and difficulty involved. Namely, fast response thermocouples are needed, carefully installed at strategic points in the engine structure; proper amplification and a sophisticated data acquisition system is necessary for the correct interpretation of the data obtained.

One common aspect of all the above-mentioned works is that they investigated the short-term temperature swing development in the diesel engine cylinders during steady-state engine operation. Since load transients are considered to be a highly adverse engine operating condition that can lead to early material failure $[2,20,22]$, it was strongly suspected that a complete investigation of transient LHR turbocharged diesel engine operation should include the propagation of the short-term temperature variations too, as such information is lacking from the literature.

Furthermore, it has long been understood that traditional first-law analysis, which is needed for modeling the engine processes, often fails to give the engineer the best insight into the engine's operation. In order to analyze engine performance -that is, evaluate the inefficiencies associated with the various processes- the application of second-law analysis may prove successful [12]. For second-law analysis, the key concept is "availability" (or exergy). The availability content of a material represents its potential to do useful work. Unlike energy, availability can be destroyed that is a result of such phenomena as combustion, friction, mixing or throttling. The destruction of availability -usually termed irreversibility- is the source for the defective exploitation of fuel into useful mechanical work in an internal combustion engine. The reduction of irreversibilities can lead to better engine performance through a more efficient exploitation of fuel [12]. Various steady-state analyses so far have emphasized the importance of cylinder wall insulation on the reduction of combustion irreversibilities [12-16]. It seems therefore very logical to investigate the respective phenomena under transient conditions too.

The present investigation aims in studying globally the transient operation of a LHR turbocharged diesel engine by applying both energy and exergy balances to the engine cylinder and all of its sub-systems. The energy 
balance will include the response of all important engine and turbocharger variables, e.g. engine speed, fuel pump rack position, boost pressure, turbocharger speed, volumetric efficiency, heat transfer coefficients, etc., as well as the development of the interesting short-term temperature variations. Various schemes will be considered regarding insulation, i.e. plasma spray zirconia or silicon nitride, and cylinder wall materials, i.e. cast iron or aluminium. By so doing, it is believed that light will be shed into the underlying complicated heat transfer mechanism and that the magnitude of the developed temperature gradients during transients will be revealed. Finally, the analysis will extend to cover the transient response under the second-law perspective, with particular reference to the various irreversibilities. Special attention will be paid to the comparison between the results of the two thermodynamic laws. Owing to the narrow speed range of the engine in hand, only load increases under constant governor setting are investigated, which, nonetheless, play a significant role in the European Transient Cycles of heavy duty vehicles.

In order to fulfil the above goal, an experimentally validated transient diesel engine simulation code [19] has been extended to include a detailed heat transfer analysis, as well as a second-law balance for all engine processes and systems. The model incorporates some important features to account for the peculiarities of the transient operation. In the developed sub-models, improved relations are included concerning fuel injection, friction, dynamic analysis and multi-cylinder engine operation during transient conditions [19-21]. The thermodynamic model of the engine is appropriately coupled to a wall periodic heat conduction model, which uses the gas temperature variation as boundary condition throughout the engine cycle after being treated by Fourier analysis techniques.

\section{FIRST-LAW ANALYSIS}

\section{IN-CYLINDER SIMULATION PROCESS}

The present analysis does not, at the moment, include prediction of exhaust gas emissions while, on the other hand, deals with transient operation calculations on a ${ }^{\circ} \mathrm{CA}$ (degree crank angle) basis. Therefore, a singlezone model is used for the thermodynamic processes evaluation. This approach is believed to be the best compromise between accuracy and limited PC program execution time [20]. The fuel is dodecane $\left(\mathrm{C}_{12} \mathrm{H}_{26}\right)$ with a lower heating value, $L H V=42,500 \mathrm{~kJ} / \mathrm{kg}$. Perfect gas behavior is assumed. Polynomial expressions are used for the species considered concerning the evaluation of internal energy and specific heat capacities for first-law applications to the engine cylinder contents $[4,5]$. The species considered are $\mathrm{O}_{2}, \mathrm{~N}_{2}, \mathrm{CO}_{2}, \mathrm{H}_{2} \mathrm{O}$ and $\mathrm{CO}$; the latter is taken into account, using the corresponding chemical equilibrium, only when the mixture is rich and for gas temperatures exceeding $1400 \mathrm{~K}$, as for example during the early cycles of the transient event where the turbocharger lag is prominent [20].
For heat release rate predictions, the fundamental model proposed by Whitehouse and Way [32] is used. Especially during transients, the constant ' $\mathrm{K}$ ' in the (dominant) preparation rate equation of the model is correlated with the Sauter mean diameter (SMD) of the fuel droplets through a formula of the type: $K \propto(1 / S M D)^{2.5}[4,19,20]$. The effect of fuel-air equivalence ratio $\Phi$ is also taken into account through the following correction equation for the activation constant 'act',

$$
\operatorname{act}=\operatorname{act}_{\mathrm{o}} \cdot\left(\frac{\Delta \Phi}{\Phi_{\mathrm{o}}}\right)^{\mathrm{c}}
$$

where the subscript 'o' denotes reference conditions.

The improved model of Annand [1] is used to simulate heat loss $Q_{\llcorner}$to the cylinder head, walls, and piston head

$$
\begin{gathered}
\frac{d Q_{L}}{d t}=F\left\{\frac{k_{g}}{D} R^{b}\left[a\left(T_{g}-T_{w}\right)+\frac{a^{\prime}}{\omega} \frac{d T_{g}}{d t}\right]+c\left(T_{g}^{4}-T_{w}^{4}\right)\right\}= \\
=h_{g}\left(T_{g}-T_{w}\right)
\end{gathered}
$$

where a, a', b and c are constants evaluated after experimental matching at steady-state conditions, the heat transfer surface $F=2\left(\pi D^{2} / 4\right)+F^{\prime}$, with $F^{\prime}=\pi D x$, and $x$ the instantaneous cylinder height in contact with the gas $[4,20], \mathrm{k}_{\mathrm{g}}$ is the gas thermal conductivity, and the Reynolds number $R e$ is calculated with a characteristic speed derived from a $k-\varepsilon$ turbulence model and a characteristic length equal to the piston diameter. The temperature $T_{w}$ used above corresponds to the cylinder liner. Based on previous, experimentally validated, findings for this type of engines [e.g. 5], the piston crown temperature is assumed to be $50 \mathrm{~K}$ higher and the cylinder head $100 \mathrm{~K}$ higher than the current one of the liner that is computed from Eq. (2).

\section{WALL PERIODIC HEAT CONDUCTION MODEL}

In the present study, a detailed heat transfer mechanism scheme is applied for the engine cylinder as illustrated in Fig. 1, which also shows the definition of temperature swing amplitude. By so doing, the temperature distribution and the respective heat flux are studied from the gas to the cylinder wall up to the coolant (convection from the gas to the internal wall surface and from the external wall surface to the coolant, and conduction across the insulated cylinder wall). The following, usually applied and well justified, assumptions are made concerning the wall temperature computation $[2,4,5]$ :

- Heat transfer by conduction through the walls is onedimensional,

- The properties of the cylinder wall and the insulators remain constant with temperature and time, and 
- The coolant temperature $T_{\mathrm{c}}$ is constant and known a priori.

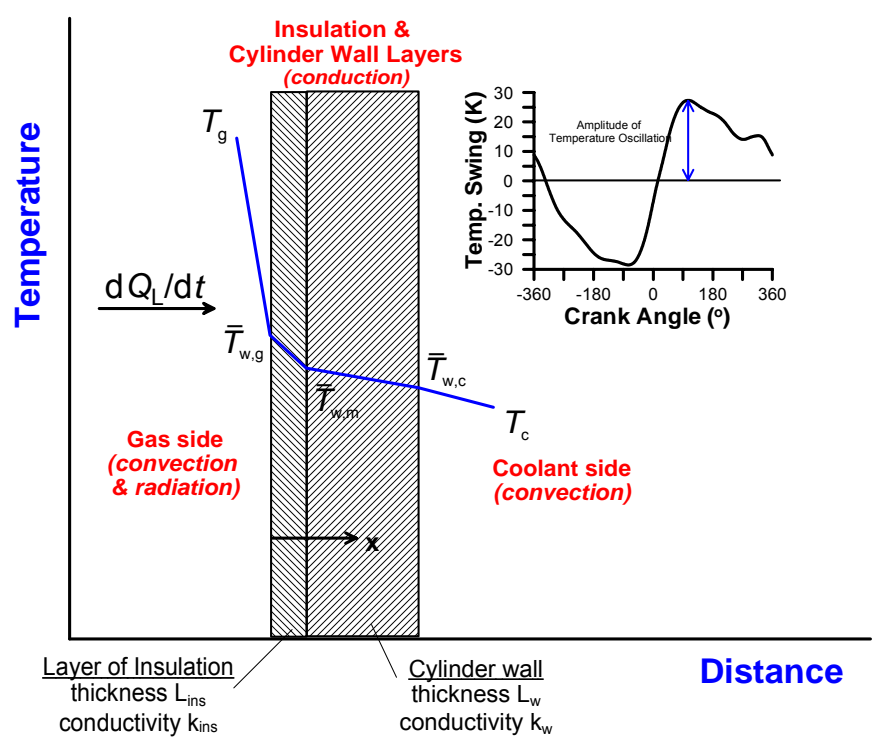

Fig. 1. Typical heat transfer scheme for engine cylinder, incl. definition of temperature swing amplitude

The heat transfer rate from the gas to the walls is a harmonic function of time, with a period of one engine cycle. As a result of it, periodic temperature waves propagate into the wall structure, which nonetheless die out already at a small distance (of very few $\mathrm{mm}$ ) from the wall inside surface, beyond which the temperature distribution is at steady-state [2].

In order to calculate the heat transfer rate through a certain location of the combustion chamber wall, during a complete engine cycle, the unsteady heat conduction equation must be solved with the appropriate boundary conditions. The total temperature, i.e. steady-state plus time-periodic, $T(x, t)$, at any point $x$ within the wall and at any time $t$, should satisfy the unsteady one-dimensional heat conduction equation [33]

$$
\frac{\partial \mathrm{T}}{\partial \mathrm{t}}=\alpha \frac{\partial^{2} \mathrm{~T}}{\partial \mathrm{x}^{2}}
$$

where $\alpha$ is the wall thermal diffusivity. The solution of this equation is accomplished by decomposing the problem into its steady-state and time-periodic components.

\section{Steady-State Heat Conduction Problem}

Applying the boundary conditions to all wall sides (gas side, coolant side and end of insulation side) of the fourstroke diesel engine, the following equation for the general case is obtained, where also a layer of insulation is present [33] (see also Fig. 1)

$$
\begin{aligned}
& \frac{1}{4 \pi} \int_{0}^{4 \pi} \frac{d Q_{L}}{d \varphi} d \varphi=F \cdot \frac{k_{\text {ins }}}{L_{\text {ins }}}\left(\bar{T}_{w, g}-\bar{T}_{w, m}\right)= \\
& =F \cdot \frac{k_{w}}{L_{w}}\left(\bar{T}_{w, m}-\bar{T}_{w, c}\right)=F \cdot h_{c}\left(\bar{T}_{w, c}-T_{c}\right)
\end{aligned}
$$

where $d Q_{L} / d \varphi$ is the heat flux computed from Eq. (2), bearing also in mind that $d \varphi=6 \mathrm{Ndt}$, $\mathrm{L}_{\text {ins }}$ the thickness of the insulation layer with $k_{\text {ins }}$ its thermal conductivity, $L_{w}$ the cylinder wall thickness with $k_{w}$ its thermal conductivity, $h_{c}$ the heat transfer coefficient from the external wall side (respective temperature $\bar{T}_{w, c}$ ) to the coolant; the overbar denotes mean temperatures over an engine cycle. Eqs (4) are solved for the three unknown variables, i.e. the wall temperatures $\bar{T}_{w, g}, \bar{T}_{w, m}$ and $\bar{T}_{w, c}$, which change from cycle to cycle during the transient event but are considered to remain constant throughout the cycle, hence the "steady-state" definition.

From the linear variation of mean temperature $\overline{\mathrm{T}}$ inside the insulated wall with distance $x$ from the wall inside surface (Fig. 1), we get

$$
\begin{gathered}
\bar{T}(x)=\bar{T}_{w, g}-\frac{x}{L_{i n s}}\left(\bar{T}_{w, g}-\bar{T}_{w, m}\right) \quad \text { for } 0<x<L_{i n s} \\
\bar{T}(x)=\bar{T}_{w, m}-\frac{x-L_{i n s}}{L_{w}}\left(\bar{T}_{w, m}-\bar{T}_{w, c}\right) \text { for } L_{i n s}<x<L_{i n s}+L_{w}
\end{gathered}
$$

\section{$\underline{\text { Time-periodic heat conduction problem }}$}

The detailed formulation of the time-periodic heat conduction problem has been analyzed in detail by Rakopoulos et al. $[26,27]$. In this paper, only a brief outline will be given highlighting the basic equations applied. The time-periodic part $T_{p}(x, t)$, at any point $x$ within the wall and at any time $t$, will satisfy the unsteady one-dimensional heat conduction equation within a parallel slab, having a thermal diffusivity $\alpha$,

$$
\frac{\partial T_{p}}{\partial t}=\alpha \frac{\partial^{2} T_{p}}{\partial x^{2}}
$$

This continuous partial differential equation can be solved analytically [34] using Fourier analysis techniques, even though during transients $T_{p}(x, t)$ is not a periodic function. Eq. (5) is subjected to the boundary condition of the inside wall surface, at $x=0$, to be exposed to the gas temperature that varies periodically in time [33],

$$
-\left.\mathrm{k}_{\text {ins }} \frac{\partial \mathrm{T}_{\mathrm{p}}}{\partial \mathrm{x}}\right|_{\mathrm{x}=0}=\bar{h}_{\mathrm{g}}\left(\mathrm{T}_{\mathrm{p}}-\mathrm{T}_{\mathrm{pg}}\right)
$$

with the respective mean heat transfer coefficient from gas to cylinder wall 


$$
\bar{h}_{g}=\frac{1}{4 \pi} \int_{0}^{4 \pi} h_{g} d \varphi
$$

The time-periodic part of gas temperature $T_{p g}(t)$ is expressed as a Fourier series, in the following form $[35,3]$,

$$
T_{p g}(t)=\sum_{n=1}^{\infty}\left[A_{n} \cos \left(\frac{2 \pi n}{T_{0}} t\right)+B_{n} \sin \left(\frac{2 \pi n}{T_{0}} t\right)\right]
$$

where $T_{0}$ is the time period of the temperature oscillation, which for a four-stroke engine corresponds to a frequency that is half the engine speed. For the wall temperature we get [36]:

$$
T_{p}=\sum_{n=1}^{\infty} \frac{\exp \left(-\xi_{n} x\right)}{\sqrt{1+2 \zeta_{n}+2 \zeta_{n}^{2}}}\left[C_{n} \cos \left(\frac{2 \pi n}{T_{0}} t-\xi_{n} x-\theta_{n}-\delta_{n}\right)\right]
$$

where the following quantities have been defined ( $\mathrm{k}_{\mathrm{ins}} \equiv \mathrm{k}_{\mathrm{w}}$ for the non-insulated wall case):

$$
\begin{gathered}
C_{n}=\sqrt{A_{n}^{2}+B_{n}^{2}} \\
A_{n}=\frac{2}{T_{0}} \int_{0}^{T_{o}} T_{g}(t) \cos \left(\frac{2 \pi n}{T_{0}} t\right) d t \\
B_{n}=\frac{2}{T_{0}} \int_{0}^{T_{0}} T_{g}(t) \sin \left(\frac{2 \pi n}{T_{0}} t\right) d t \\
A_{o}=\bar{T}_{g}=\frac{1}{T_{0}} \int_{0}^{T_{0}} T_{g}(t) d t \\
\delta_{n}=\tan ^{-1}\left(B_{n} / A_{n}\right) \\
\xi_{n}=\sqrt{\pi n / \alpha T_{0}} \\
\theta_{n}=\tan ^{-1}\left(\frac{1}{1+\left(1 / \zeta_{n}\right)}\right) \\
\zeta_{n} \xi_{n}\left(k_{i n s} / h\right)=\sqrt{\pi n k_{i n s}^{2} / \alpha T_{0} h^{2}}
\end{gathered}
$$

Term $C_{n} \cos \left(\xi_{n} x\right)=C_{n} \cos \left[\left(\sqrt{\pi n / \alpha T_{0}}\right) x\right]$ from Eq. (8) represents a cosine wave of amplitude $C_{n}$ and wavelength $x_{0}$ calculated from the condition $\left(\sqrt{\pi \mathrm{n} / \alpha \mathrm{T}_{0}}\right) x_{0}=2 \pi$ and $n=1$, i.e.

$$
x_{0}=\sqrt{\pi \alpha T_{0}}
$$

\section{$\underline{\text { Computational procedure }}$}

The computational process begins with the cylinder steady-state calculations where a mean, gas-side, wall temperature is assumed. By so doing, the calculation of the heat flux from Eq. (2) is made possible. At the end of the first 'trial' cycle, a balance has been reached between the total, during the cycle, gas-to-inside wall heat transfer and the corresponding heat conducted through the walls; a new improved estimate of cylinder wall temperature can be computed and used for the next engine cycle iteration using Eqs (4). Iterations continue in this 'external loop', until calculations lead to convergence. After the final convergence of the whole thermodynamic cycle, the transient cycles commence (provided that all other interesting properties, i.e. cylinder pressure and temperature at the beginning of the cycle, indicated mean effective pressure etc., have also converged). During the transient event, the mean temperatures obtained from Eqs (4) at the end of each cycle are used for the computation of the corresponding heat flux during the next transient cycle and so on. At the end of each transient cycle, the values of the gas temperatures in the whole cycle are used for calculating its Fourier sine and cosine coefficients (Eqs (9)). Then, the computations proceed concerning the time-periodic part of wall temperatures (Eq. (8)) and the corresponding heat transfer rates.

Various sophisticated sub-models have been incorporated in the main code, which have been analyzed in previous publications [19-21]. These deal with the following:

\section{MULTI-CYLINDER ENGINE MODELING}

At steady-state operation the performance of each cylinder is essentially the same, due to the quasi-steady position of the governor clutch resulting in the same amount of fuel being injected per cycle, and the quasisteady turbocharger compressor operating point. Under transient operation, however, each cylinder experiences different fuelings and air mass flow-rates during the same engine cycle. This occurs due to the combined effect of: a) the continuous movement of the fuel pump rack that is initiated by a load or speed change, and b) the continuous movement of the turbocharger compressor operating point. As regards speed changes, only the first cycles are practically affected. However, when load changes are investigated, significant variations can be experienced throughout the whole transient cycle. The usual approach, here, is the solution of the governing equations for one cylinder and the subsequent use of suitable phasing images of this cylinder's behavior. This approach is widely popular for limiting the computational time [17]. Contrary to this, the present research group has developed a true multicylinder engine model. Here, all the governing differential and algebraic equations are solved individually for every one cylinder of the six-cylinder engine under study according to the current values of the fuel pump rack position and turbocharger compressor flow. This results in (significant) differentiations in both fueling and air mass flow-rates for each cylinder during the same cycle of a transient event. The current approach has, of course, the drawback of increasing the computational time almost linearly to the number of cylinders involved. 


\section{FUEL PUMP OPERATION}

Instead of using steady-state fuel pump curves during transients, a fuel injection model, experimentally validated at steady-state conditions, is applied. Thus, simulation of the fuel pump-injector lift mechanism is accomplished, taking into account the delivery valve and injector needle motion [37]. The unsteady gas flow equations are solved using the method of characteristics, providing the dynamic injection timing as well as the duration and the rate of injection for each cylinder at each transient cycle. The obvious advantage here is that the transient operation of the fuel pump is also taken into account. This is mainly accomplished through the fuel pump residual pressure value, which is built up together with the other variables during the transient event.

\section{FRICTION}

For the calculation of friction inside the cylinder, the method proposed by Taraza et al. [38] is adopted. It describes the non-steady profile of friction torque during each cycle based on fundamental friction analysis. Here, the total amount of friction is divided into four parts, i.e. piston rings assembly, loaded bearings, valve train and auxiliaries. Total friction torque at each ${ }^{\circ} \mathrm{CA}$ is the sum of the above terms; it varies during the engine cycle, especially around 'hot' TDC, unlike the usually applied 'mean' fmep equations where friction torque remains constant throughout each cycle $[20,38,39]$.

\section{TURBOCHARGER}

The mathematical representation of compressor and turbine characteristics is necessary to calculate the interaction between turbocharger and diesel engine. The use of compressor and turbine performance characteristics is adopted, as provided by the manufacturer. These give the interdependence between isentropic efficiency $\eta_{\text {is, }}$, pressure ratio $r$, mass flow rate $\dot{\mathrm{m}}$ and rotational speed $\mathrm{N}_{\mathrm{TC}}$ [20], i.e.

$$
\eta_{\text {isc }}, r_{C}=f_{C}\left(\dot{m}_{C}, N_{T C}\right)
$$

for the compressor, while for the turbine

$$
\dot{\mathrm{m}}_{\mathrm{T}}=\mathrm{f}_{\mathrm{T}}\left(\mathrm{r}_{\mathrm{T}}, \frac{\mathrm{u}}{\mathrm{c}_{\mathrm{o}}}\right)
$$

with $\left(\mathrm{u} / \mathrm{c}_{\mathrm{o}}\right)_{T}$ the turbine blade to speed ratio.

\section{CRANKSHAFT ANGULAR MOMENTUM EQUILIBRIUM}

The conservation of angular momentum applied to the engine crankshaft yields

$$
M_{e}(\varphi, \omega)-M_{f r}(\varphi, \omega)_{\text {trans }}-M_{\text {Load }}(\omega)=G_{\text {tot }} \frac{d \omega}{d t}
$$

where $G_{\text {tot }}$ is the engine-flywheel-load mass moment of inertia reduced to the crankshaft axis, and $M_{e}(\varphi, \omega)$ the instantaneous value of the engine torque [20]. Also,

$$
\mathrm{M}_{\text {Load }}(\omega)=\mathrm{c} \omega^{2}
$$

is the load torque for the hydraulic brake coupled to the engine examined, and $\mathrm{M}_{\mathrm{fr}}(\varphi, \omega)_{\text {trans }}$ stands for the friction torque term computed using the above-mentioned Taraza et al. model [38]. The block diagram of the whole simulation model developed is illustrated in Fig. 2.

\section{EXPERIMENTAL PROCEDURE}

The objective of the experimental test bed developed was to validate the transient performance of the engine simulation. To accomplish this task the engine was coupled to a hydraulic brake (dynamometer). The experimental investigation was conducted on a (uninsulated) MWM TbRHS 518S, 6-cylinder, turbocharged and aftercooled, medium-high speed diesel engine. The engine is permanently coupled to a Schenck hydraulic dynamometer. Details about the experimental setup can be found in Ref. [19]. The basic data for the engine are given in Table 1. A schematic arrangement of the engine-load-acquisition setup is illustrated in Fig. 3.

Table 1. Engine Data

\begin{tabular}{|cc|}
\hline Engine Type & $\begin{array}{c}\text { 6-cylinder, 4-stroke, } \\
\text { turbocharged and } \\
\text { aftercooled, heavy-duty } \\
\text { diesel engine }\end{array}$ \\
\hline Speed Range & $1000 \div 1500 \mathrm{rpm}$ \\
\hline Bore / Stroke & $140 \mathrm{~mm} / 180 \mathrm{~mm}$ \\
\hline Maximum Power & $236 \mathrm{~kW} @ 1500 \mathrm{rpm}$ \\
\hline Maximum Torque & $1520 \mathrm{Nm} \mathrm{@} \mathrm{1250} \mathrm{rpm}$ \\
\hline $\begin{array}{c}\text { Total Moment of } \\
\text { Inertia }\end{array}$ & $15.60 \mathrm{~kg} \mathrm{~m}{ }^{2}$ \\
\hline
\end{tabular}

The first requirement from the engine test bed instrumentation was to investigate the steady-state performance of the examined engine. For this purpose, an extended series of steady-state trials was conducted in order on the one hand to examine the model's predictive capabilities and on the other to calibrate successfully the individual sub-models, particularly the heat transfer one. The investigation of transient operation was the next task. Since the particular engine is one with a relatively small speed range, mainly load changes (increases) with constant governor setting were examined. A typical example of a conducted transient experiment is given in Fig. 4. Here, the initial load was $10 \%$ of the full engine load at $1180 \mathrm{rpm}$. The final load applied was almost $50 \%$ of the full engine load. The matching between experimental and predicted transient responses was satisfactory for both engine and turbocharger variables (engine speed, fuel pump rack position and boost pressure). 


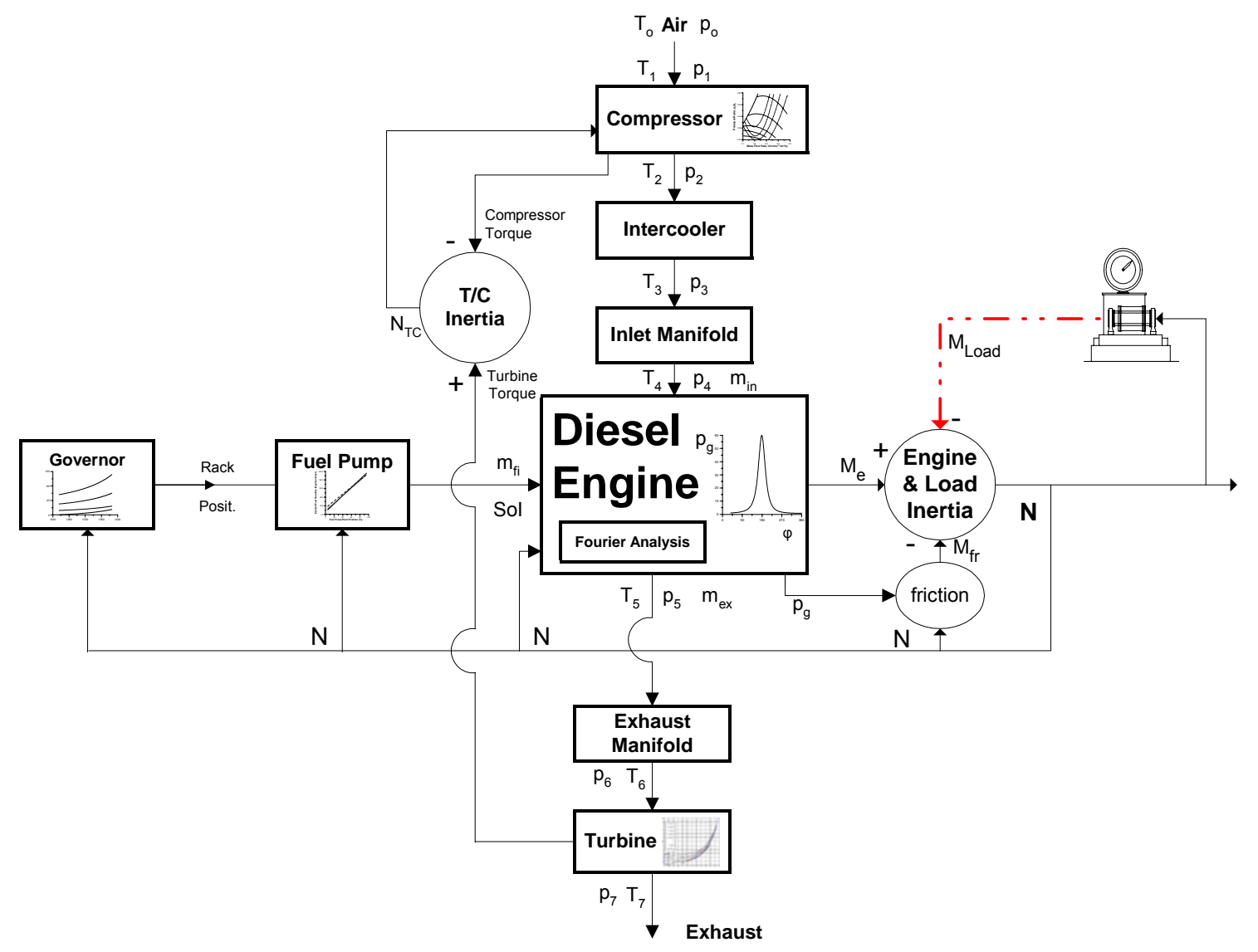

Fig. 2. Block diagram of the developed simulation code
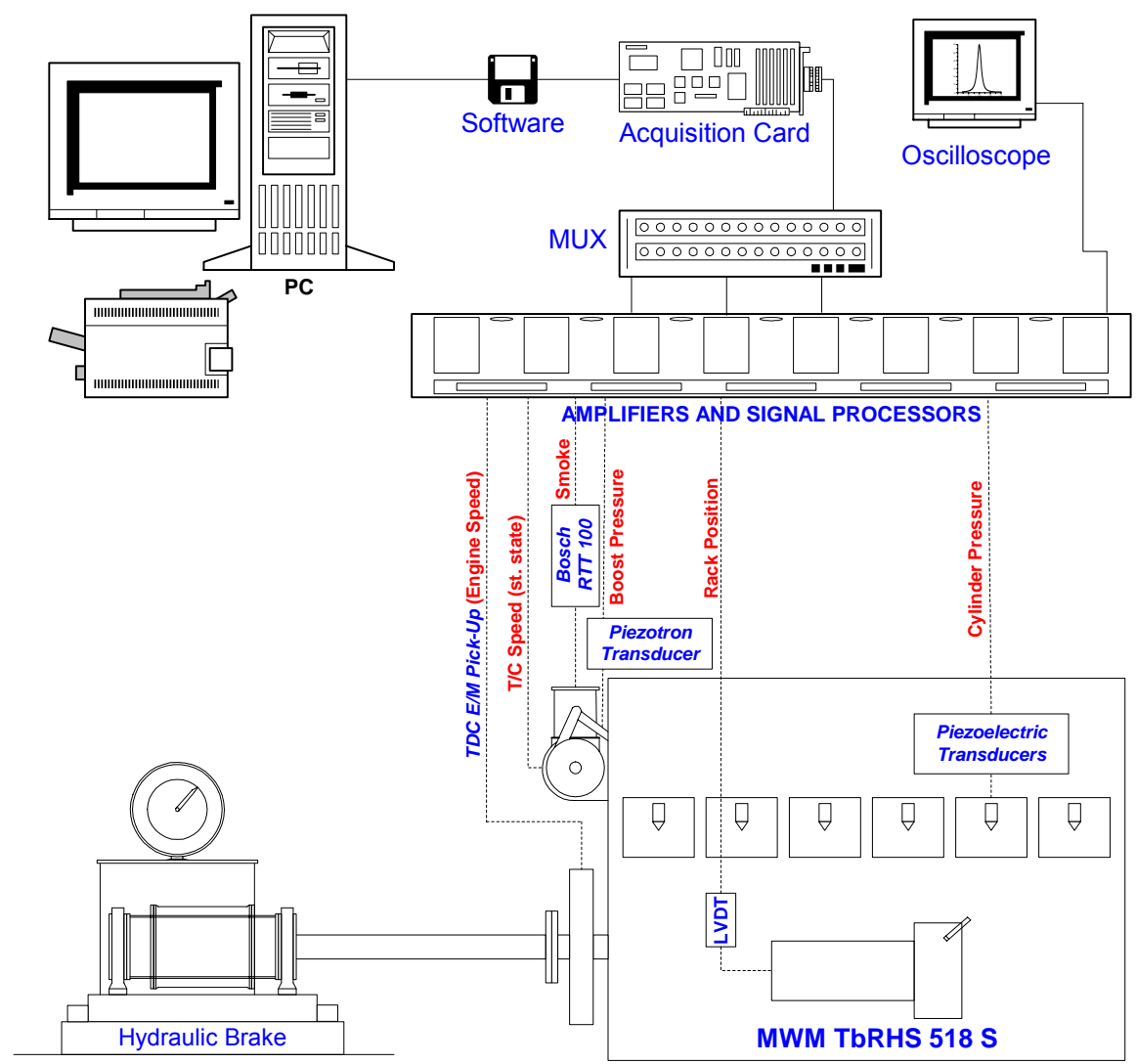

Fig. 3. Schematic arrangement of the experimental set-up 


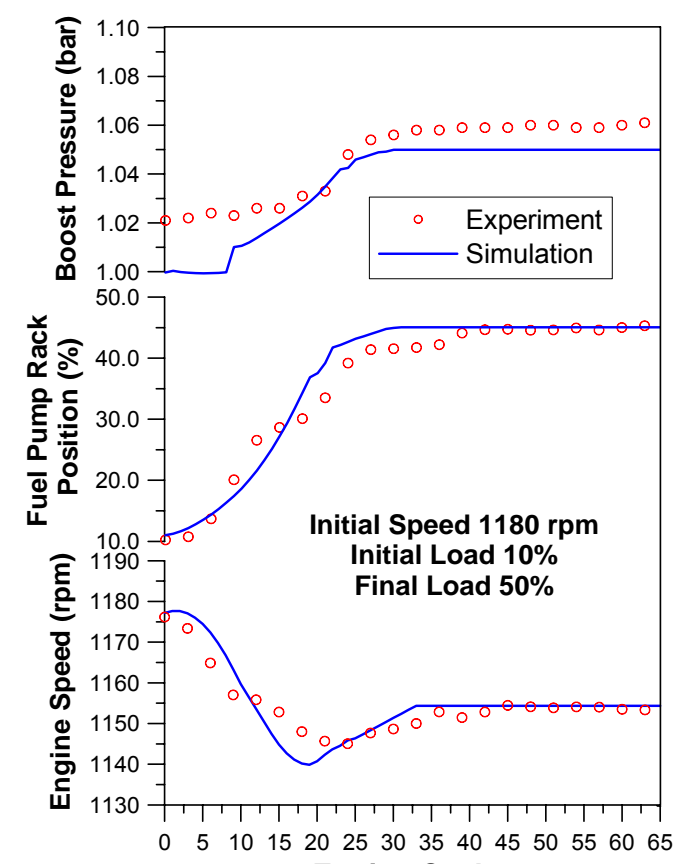

Engine Cycle

Fig. 4. Experimental and predicted engine transient response to an increase in load.

\section{INSULATION SCHEMES AND TRANSIENT SCHEDULES}

The baseline, non-insulated, case configuration is that corresponding to the engine in hand, possessing a cast iron wall thickness of $10 \mathrm{~mm}$. Table 2 illustrates the four, widely different, insulation schemes considered for the theoretical study. A uniform coating is assumed for piston crown, cylinder head and wall surface. The main thermal properties of the cylinder wall materials and insulators (ceramics) used are given in Table 3.

Table 2. Summary of the insulation schemes

\begin{tabular}{c|ccc}
\hline & $\begin{array}{c}\text { Cylinder Wall } \\
\text { Material }\end{array}$ & Insulation & $\begin{array}{c}\text { Depth of } \\
\text { Insulation }\end{array}$ \\
\hline 1 & Cast iron & - & - \\
2 & Cast iron & SN & $4.0 \mathrm{~mm}$ \\
3 & Cast iron & PSZ & $1.0 \mathrm{~mm}$ \\
4 & Cast iron & PSZ & $1.5 \mathrm{~mm}$ \\
5 & Aluminium & - & - \\
\hline
\end{tabular}

Table 3. Thermal properties for wall materials and insulators

\begin{tabular}{c|cc}
\hline & $\begin{array}{c}\text { Conductivity 'k' } \\
(\mathrm{W} / \mathrm{m} \mathrm{K})\end{array}$ & $\begin{array}{c}\text { Thermal Diffusivity } \\
\text { ' } \alpha \text { ' }\left(\mathrm{m}^{2} / \mathrm{s}\right)\end{array}$ \\
\hline Cast iron & 54 & $14 \times 10^{-6}$ \\
Aluminium & 180 & $78 \times 10^{-6}$ \\
SN & 10 & $2.80 \times 10^{-6}$ \\
PSZ & 1.0 & $0.90 \times 10^{-6}$ \\
\hline
\end{tabular}

One of the main effects of engine heat insulation is the significant rise of combustion chamber wall temperatures and thus the higher thermal loading of the engine. This loading is assumed to be withstood by the engine, without paying any attention in this study to the examination of the developed thermal stresses and component deformations. All the results provided below derive from the application of the simulation model.

When comparing the transient response of different engine configurations, it is imperative that the initial operating point is kept the same for all examined cases. For the present study, at the initial engine speed of $1180 \mathrm{rpm}$, the initial load always corresponded to the same value of constant ' $c$ ' in the load torque term (Eq. (14)). The latter was $10 \%$ of the engine's maximum load. Afterwards, a $650 \%$ relative load-change was abruptly applied. The final conditions roughly correspond to $75 \%$ engine load. The case with a $10-95 \%$ load-change will also be depicted in order to enhance the importance of some of the obtained results.

\section{RESULTS AND DISCUSSION}

Figure 5, which is provided for quantitative reasons only, illustrates the response of the corresponding mean, gasside cylinder wall temperature $\overline{\mathrm{T}}_{\mathrm{w}, \mathrm{g}}$ for each insulation scheme studied during the examined transient load increase. As expected from the respective steady-state studies $[2,3,5,26,27]$, a higher degree of insulation increases the wall temperatures throughout the transient event; the latter is enhanced with higher loading.

In Figs 6 and 7, the mean heat transfer coefficient $\bar{h}_{g}$ (defined by Eq. (6b)) from gas to cylinder wall, and the respective mean heat flux are depicted. These heat transfer variables agree with the results reached by Assanis and Heywood [2] for the steady-state operation of a similarly rated turbocharged diesel engine.

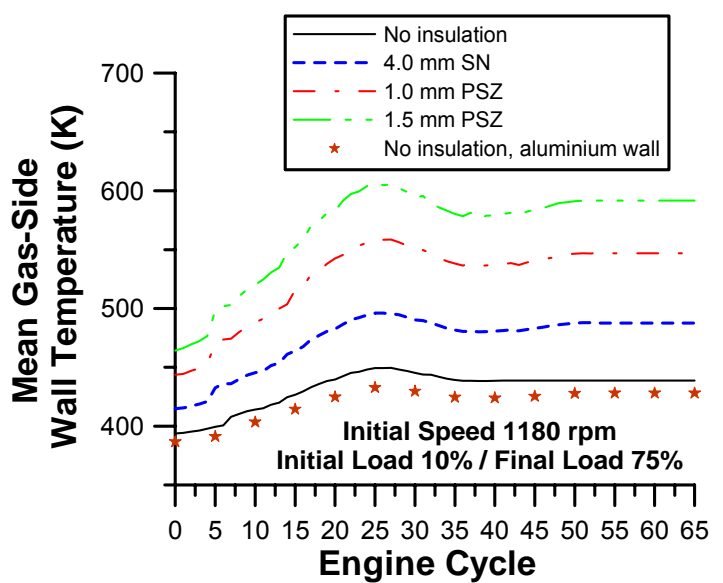

Fig. 5. Response of mean gas-side wall temperatures during the transient event (unless otherwise noted, the cylinder wall is cast iron) 


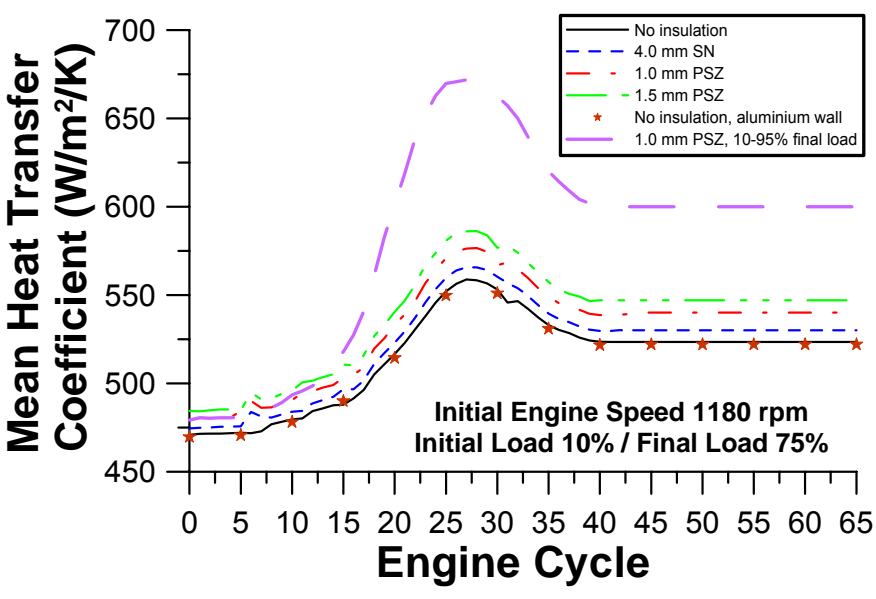

Fig. 6. Response of mean heat transfer coefficient from gas to cylinder wall to an increase in load (unless otherwise noted, the cylinder wall is cast iron and the load-increase is $10-75 \%$ )

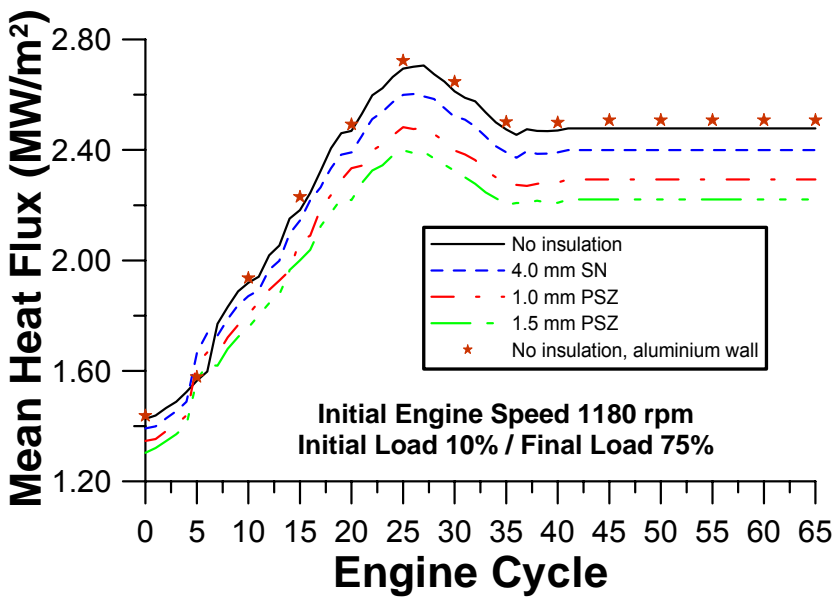

Fig. 7. Response of mean gas to cylinder wall heat flux to an increase in load (unless otherwise noted, the cylinder wall is cast iron)

It is interesting to note that although the heat transfer coefficient is increased with increasing degree of insulation schemes, as was expected due to the higher gas temperatures involved, the respective heat flux exhibits an opposite behavior. This is attributed to the reduced difference between gas and gas-side wall temperatures $\left(\mathrm{T}_{\mathrm{g}}-\overline{\mathrm{T}}_{\mathrm{wg}}\right)$ when the insulation increases, a fact that can lead eventually to smaller requirements from the cooling system.

In Fig. 8, the response of six important engine parameter values is illustrated, i.e., engine speed, fuel pump rack position, air-fuel equivalence ratio, boost pressure, turbocharger speed and volumetric efficiency. Clearly, the engine speed, as well as the other variables of the engine and turbocharger, is only slightly affected by the level of temperatures inside the cylinder, with the higher insulated cases leading to smaller speed drops. This was also the result reached by Watson [17] and Schorn et al. [23], although these researchers did not investigate the effect of such a high level of wall insulation during transients.

The most notable effect of transient turbocharged diesel engine operation is the turbocharger lag [20]. This is pronounced with the continuous increase in engine rating, and it is usually realized with the increased black smoke emissions. Turbocharger lag is caused because of the lack of mechanical connection between turbocharger compressor and engine crankshaft. Consequently, the power delivered to the turbine must first accelerate the turbocharger shaft in order for the compressor to be able to produce the increased boost pressure. Other related delays concern the use of fuel limiters, heat losses to the cylinder and exhaust manifold walls, and the acceleration of the rotating masses. Therefore, a higher wall temperature is generally expected to improve the turbocharger lag and thus speed response, as the effect of one of the abovementioned 'decelerators' is considerably limited. Similar effects have been reported for the case where the exhaust manifold wall is insulated [23]. However, the improvement in turbocharger lag is not so pronounced for the present engine-load configuration, since its high total mass moment of inertia slows down the whole transient event (see also Fig. 13 concerning the respective exhaust gas availability).

Closer examination of the curves in Fig. 8 shows that the volumetric efficiency ${ }^{1}$ alone, exhibits a differentiated profile. Namely, a decreasing trend is observed with higher degree of insulation schemes. The increased level of cylinder wall temperatures during the induction process transfers heat to the incoming charge, thus reducing its density and hence volumetric efficiency throughout the transient event. This behavior goes along with the results reached by previous researchers for steady-state operation.

Figure 9 extends the results of Fig. 8 by showing the response of the transient indicated specific fuel consumption (isfc) of the engine, highlighting the small benefit gained from the insulation. An increased level of temperatures during each cycle leads to 'fuller' pressures diagrams due to increased expansion work and slightly reduced pumping losses, thus increasing the efficiency up to $3.65 \%$ for the $1.5 \mathrm{~mm} \mathrm{PSZ}$ case at the 20th cycle of the transient event. It is obvious that the engine handles now the transient test in a slightly more efficient manner. This confirms the steady-state results by Wong et al. [10], who reported an increase in the engine efficiency with increasing temperature swings; this is explained with reference to Fig. 10 later in this Section, concerning the connection between degree of insulation and temperature swings. However, the increase in isfc is much smaller than would be expected judging from the corresponding increase in gas temperatures. Various theories have been reported on the subject, with the most profound being the one proposed by Alkidas [8].

\footnotetext{
${ }^{1}$ based on atmospheric conditions.
} 

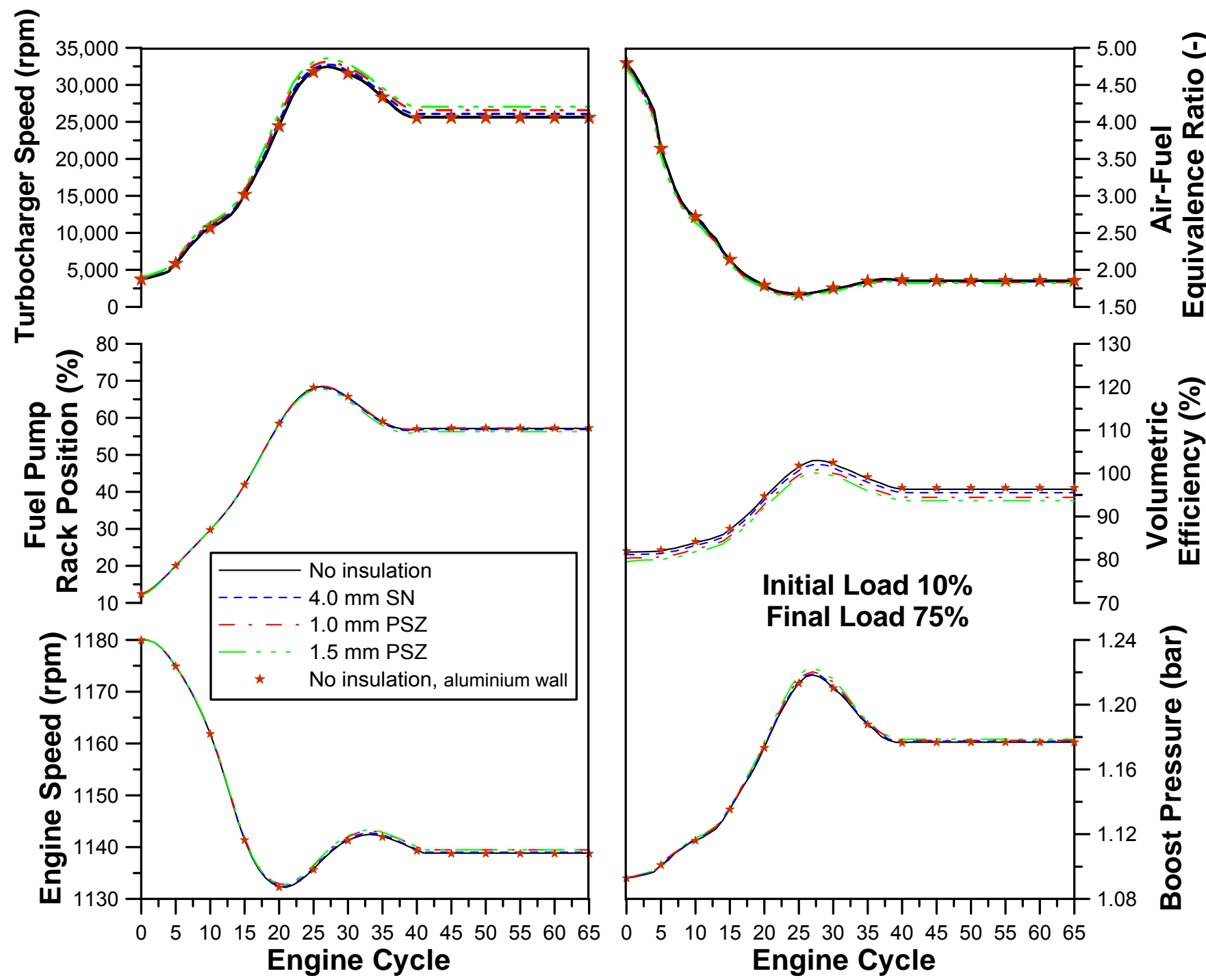

Fig. 8. Response of various engine parameters to an increase in load (unless otherwise noted, the cylinder wall is cast iron)

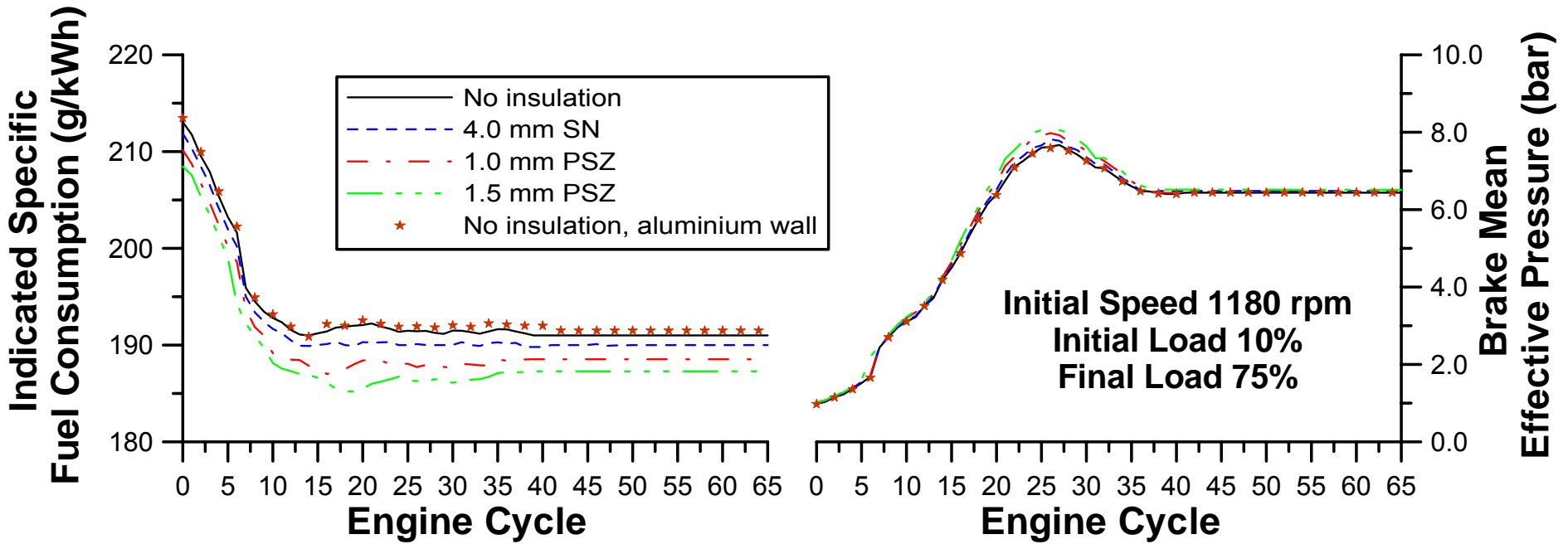

Fig. 9. Response of various engine parameters to an increase in load (unless otherwise noted, the cylinder wall is cast iron) 
$\mathrm{He}$ argued that an increased level of insulation led to some kind of 'deterioration' of the combustion process by shifting a larger part of the fuel burning into the diffusion phase, i.e. later in the cycle [26]. Schwartz et al. [40], extending the results of Alkidas, concluded that an improved time phasing of premixed and diffusion burning must be accomplished if a desirable heat release is to be derived in a LHR engine, as the heat release pattern exhibits a great sensitivity to even small changes.

As the right sub-diagram of Fig. 9 demonstrates, the response of the bmep is also affected by the degree of insulation, with the highly insulated cases exhibiting higher values. This happens because of the combined effect of improved isfc, decrease in the volumetric efficiency, and, mainly, change in the amount of injected fuel during transients due to the transient operation of the fuel pump.

Some researchers of steady-state LHR engine operation have reported a decrease in the bmep with increasing insulation $[9,26]$. This conflicting behavior of bmep development, when comparing steady-state and transient tests, can be explained if one looks deeper into the respective principles. As mentioned previously, when comparing different insulated engine configurations during transients, it is imperative that the initial operating point is kept the same. For the steady-state runs, where a decrease in bmep was observed with higher insulations, the case was different. Namely, constant airfuel ratio was assumed for each insulated case examined $[9,26,27]$. This fact is not valid for our transient cycles, since the transient operation of the fuel pump differentiates the amount of injected fuel from the respective steady-state fuel pump curves, and the turbocharger lag alters the amount of air-mass flow rate into the engine cylinders.

In Figs 8 and 9 the difference observed between aluminium and cast iron non-insulated walls is modest, proving the small effect of the cylinder wall material on the cycle transient response (although the respective profiles of the wall temperatures differentiate, as was illustrated in Fig. 5). The same negligible difference is observed if similarly insulated cases are examined (e.g. cast iron or aluminium wall coated with $1.0 \mathrm{~mm}$ PSZ). Clearly, it is the insulator's thermal properties that are primarily responsible for the decrease in the total thermal conductivity of the insulated cylinder wall that determines the engine's transient performance (see also Fig. 1 and Fig. 18 in the next Section) as shown by the expression

$$
k_{\text {ins.w }}=\left(L_{\text {ins }}+L_{w}\right) /\left(\frac{L_{\text {ins }}}{k_{\text {ins }}}+\frac{L_{w}}{k_{w}}\right)
$$

The study of the temperature swings during transients is the next task. Fig. 10 focuses on the short-term temperature oscillations during the transient event, showing the response of the amplitude of the swing (see Fig. 1 for the definition of temperature swing amplitude). Whereas in the base, non-insulated, case the amplitude of the oscillation is about $2-3 \mathrm{~K}$, values of up to $64 \mathrm{~K}$ at cycle 23 are experienced for the $10-95 \%$ load-change when the engine is coated with $1.0 \mathrm{~mm}$ PSZ. These findings go along with the results reached by Rakopoulos et al. $[26,27]$ for steady-state operation of a naturally aspirated diesel engine. Assanis and Heywood [2] reported even greater values for the amplitude of the temperature swing, assuming a much lower thermal conductivity for the PSZ coating. From Fig. 10 it is also concluded that the increase in thickness from 1 to 1.5 $\mathrm{mm}$ PSZ has a rather modest effect on the temperature swing, whereas there is no practical difference between cast iron and aluminium wall. What it should be mentioned here, is the high rate of change of the swing amplitude between cycles 5 and 25, where the main part of the increased fueling takes place. This rate is of the order of $4 \mathrm{~K}$ per cycle for the $10-95 \%$ load change or $2 \mathrm{~K}$ per cycle for the $10-75 \%$ one, and is responsible for the increased thermal loading that is experienced by the engine structure during the transient event.

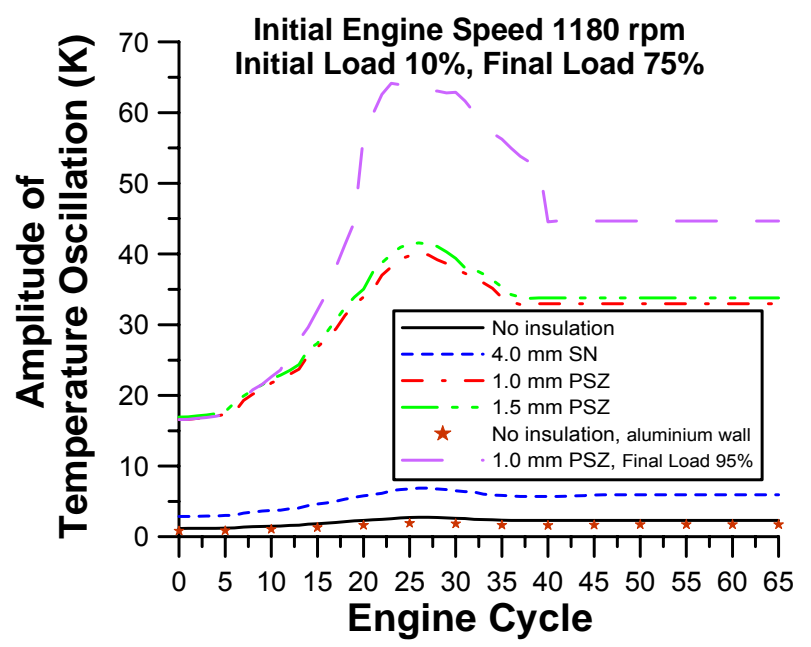

Fig. 10. Response of the temperature swing amplitude to an increase in load (unless otherwise noted, the cylinder wall is cast iron and the load-change $10-75 \%$ )

Figure 11 provides in more detail the cylinder inside wall temperature oscillation swings against crank angle, for an intermediate cycle of the transient event. A first observation is that the shape of all these curves is similar, a fact that is explained as follows. During the intake stroke the wall surface is cooled down due to heat transfer from the higher temperature wall to the cooler incoming air. The wall temperature rises during the last stages of the compression stroke, because of heat transfer to the wall from the then higher temperature compressed air. During the middle and last stages of the expansion stroke, the wall temperature decreases because of the decreasing gas temperatures. These wall temperature oscillations have been found to increase 
with fueling [26]. They also increase with the increasing degree of insulation, however at a decreasing rate. This behavior is explained as follows.

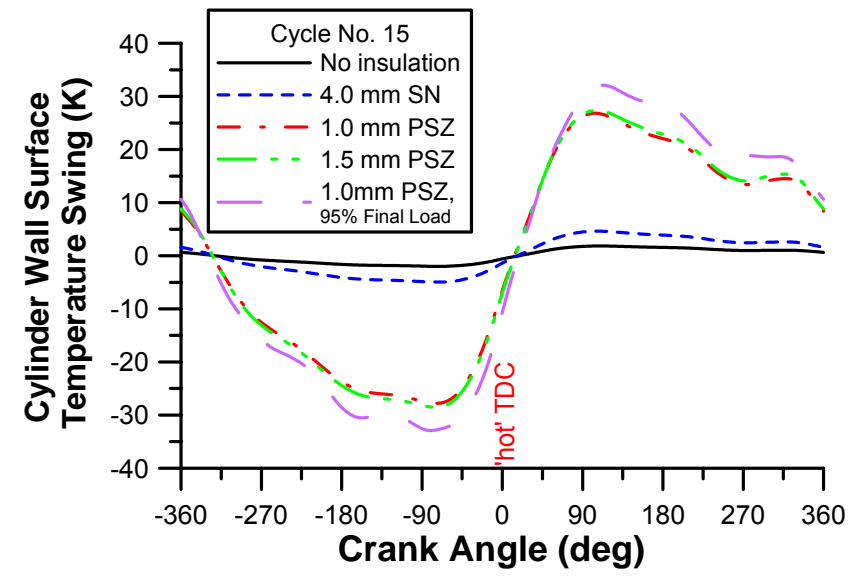

Fig. 11. Cylinder wall inside temperature oscillation swings against crank angle, during an intermediate cycle of the transient load increase of $10-75 \%$

From Eq. (8) one can see that the wall temperature swing is proportional to the in-cylinder gas temperature levels $\left(A_{n}, B_{n}\right)$ and a decreasing function of the parameter $\zeta^{2} \propto \mathrm{k}_{\text {ins }}^{2} / \alpha \mathrm{h}^{2}$ (note that a constant engine speed was assumed, i.e., constant $\mathrm{N}=1 / \mathrm{T}_{0}$, which for the presently examined transients is not a coarse approximation since, owing to the increased moment of inertia, small engine speed drops are observed). However, the variation of heat transfer coefficient with the degree of insulation is very mild $[26,27]$, so that effectively $\zeta^{2} \propto \mathrm{k}_{\text {ins }}^{2} / \alpha$. Values of $\mathrm{k}_{\text {ins }}^{2} / \alpha$ are calculated as follows for cast iron, silicon nitride and plasma spray zirconia, respectively: $2.1 \times 10^{8}, 0.36 \times 10^{8}$ and $0.11 \times 10^{8}$ (in SI units). Thus, $\zeta^{2}$ is a decreasing function of the degree of insulation. The strong increase of the wall temperature swing with the degree of insulation can then be explained by both the higher gas temperatures (cf. Fig. 5) and the lower values of $\zeta^{2}$. Nonetheless, this increase with the degree of insulation is forwarded at a decreasing rate. This is explained by the fact that, at high degrees of insulation (e.g. for the zirconia cases), the value of $\zeta^{2}$ becomes very small with respect to 1 . Then, the influence on the wall temperature swing value derives effectively only from the relatively milder increase of the gas temperature swing with the degree of insulation.

Figure 12 illustrates the variation of wall temperature swings with depth $x$ (inside the wall) extending over a wavelength $x_{0}$, at various crank angles (instants of time) extending over the current engine cycle period $\mathrm{T}_{\mathrm{o}}$ (corresponding to $720^{\circ} \mathrm{CA}$ ), at the $15^{\text {th }}$ engine cycle of the $10-75 \%$ transient event. Profiles of similar type develop during all the other cycles of the transient event.
The strong damping of the wall temperature swings with depth $x$ is apparent. Effectively, the wall swings disappear at a depth of the order of $0.6-3 \mathrm{~mm}$ (cf. Fig. 12 for the $1.0 \mathrm{~mm}$ PSZ coating).

It can clearly be seen that when increasing the degree of insulation the amplitude of the wall temperature swings highly increases, while at the same time the corresponding depths inside which they disappear decrease. As a result thermal shock increases too.

From Eq. (8) one can see that the wall temperature swing is proportional to a decreasing function of parameter $\zeta^{2} \propto 1 / h^{2}$ (for a specific speed, i.e. constant $N \propto 1 / T_{0}$, and for the same wall material, i.e. constant $k_{\text {ins }}$ and $\alpha$ ). From Eq. (8) it can also be seen that the wall temperature swing phase shifting is an increasing function of parameter $\zeta$. The strong increase of the wall temperature swing with fueling, as the transient event develops, can then be explained by both the higher gas temperatures and gas heat transfer coefficients, i.e. lower $\zeta$ (cf. Figs 5 and 6).

The decrease of depth inside which these oscillations disappear, when increasing the degree of insulation, is explained by noting from Eq. (10) that the related wavelength $x_{0} \propto \alpha^{1 / 2}$ increases, with ' $\alpha$ ' decreasing in value with the degree of insulation. The combination of large temperature gradients with short penetration lengths, as for example in the zirconia insulation cases, results in high thermal gradients, thus leading to high cyclic thermal loading. Therefore, the material concerned should possess high fatigue durability and thermal shock resistance as well as good temperature strength.

\section{SECOND-LAW ANALYSIS}

BACKGROUND ON STEADY-STATE, LOW HEAT REJECTION, DIESEL ENGINE OPERATION

The analysis of Alkidas [13,41] showed that the higher temperature of the reactants resulting from insulation of the cylinder walls increases the flame temperature and decreases the combustion irreversibilities. At the same time, the wall insulation increases the amount of the availability term of the exhaust gas from cylinder. Rakopoulos et al. [42] concluded that the interest for LHR engines emanates from their potential to do more work by utilizing the exhaust gases in a Rankine bottoming cycle. A higher insulation significantly limits the availability destruction associated with heat transfer from the gas to the cylinder walls $[15,16]$.

This availability potential can then be extracted with the use of heat transfer devices. It is imperative that the engine working fluid should not be used for such devices, since its low temperature level would make a very poor work recovery, i.e. with the heat transfer from the cylinder walls to the cooling water the majority of the work potential is destroyed. 


\section{Cycle No. 15}
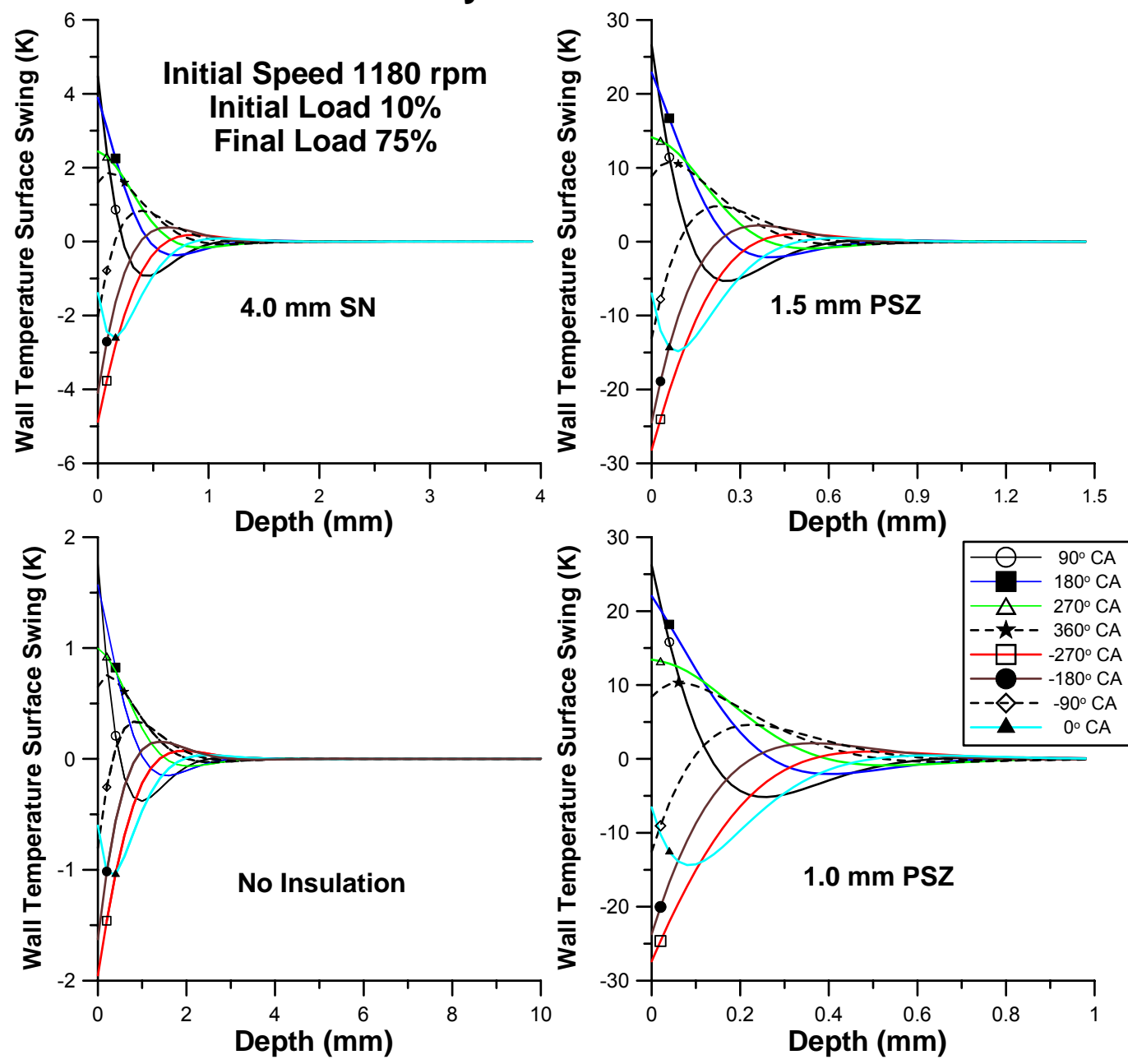

Fig. 12. Variation of wall temperature swings with depth $\mathrm{x}$ (inside the wall) extending over a wavelength, at various crank angles, for the various insulation schemes during an intermediate cycle (cycle No. 15) of the transient load increase

The second-law efficiency is also expected to increase with insulation. This is primarily attributed to the increased percentage exhaust gas exergy resulting from the previously mentioned increase in flame temperature $[13,41]$. The present investigation aims in confirming and possibly expanding the above results into the domain of transient diesel engine operation. To this aim, the second-law balance for each engine component has been computed.

\section{IN-CYLINDER CALCULATIONS}

The availability balance equations are applied to the turbocharged diesel engine and all of its subsystems, on $a{ }^{\circ} \mathrm{CA}$ basis [12]. For the engine cylinder it holds,

$$
\frac{d A_{j}}{d \varphi}=\frac{\dot{m}_{i n}^{j} b_{i n}-\dot{m}_{e x}^{j} b_{e x}}{6 N}-\frac{d A_{w}}{d \varphi}-\frac{d A_{L}}{d \varphi}+\frac{d A_{f}}{d \varphi}-\frac{d l}{d \varphi}
$$

with $\dot{\mathrm{m}}_{\text {in }}^{j}$ the incoming mass flow rate from the inlet manifold and $\dot{\mathrm{m}}_{\mathrm{ex}}^{\mathrm{j}}$ the outgoing one to the exhaust manifold for the j-th cylinder, according to the first-law analysis of the multi-cylinder engine;

$$
\frac{d A_{w}}{d \varphi}=\left(p_{g}-p_{o}\right) \frac{d V}{d \varphi}
$$

is the availability term for the work transfer with $p_{g} \equiv p_{5}$ the instantaneous cylinder pressure,

$$
\frac{d A_{L}}{d \varphi}=\frac{d Q_{L}}{d \varphi}\left(1-\frac{T_{0}}{T_{g}}\right)
$$

is the availability term for the heat transfer to the cylinder walls with $T_{g} \equiv T_{5}$ the instantaneous (uniform) cylinder 
wall temperature and $d A_{f} / d \varphi$ is the availability term for the injected fuel [12]. The term

$$
b=h-T_{o} s-\sum_{i} x_{i} \mu_{i}^{o}
$$

corresponds to the flow availability of the cylinder gas with $x_{i}$ the mole fraction of species $i$ in the mixture and $\mu_{i}^{o}$ the chemical potential of species $i$ at the restricted dead state (i.e., when thermal and mechanical equilibrium with the environment exists) [12]. The term $\mathrm{dl} / \mathrm{d} \varphi$ in Eq. (16) represents the rate of irreversibility production within the cylinder. This consists mainly of the combustion term, while inlet-valve throttling and mixing of the incoming air with the cylinder residuals have a less than $5 \%$ contribution [12]. Similar expressions were derived for the second-law balance of manifolds, turbocharger and aftercooler $[12,43,44]$.

For the whole diesel engine plant, we can define the following second-law efficiency [12],

$$
\varepsilon_{\text {tot }}=\frac{A_{w}+A_{\text {out }}}{A_{f}}
$$

where the exhaust gas to ambient flow availability is defined as (see also Fig. 2).

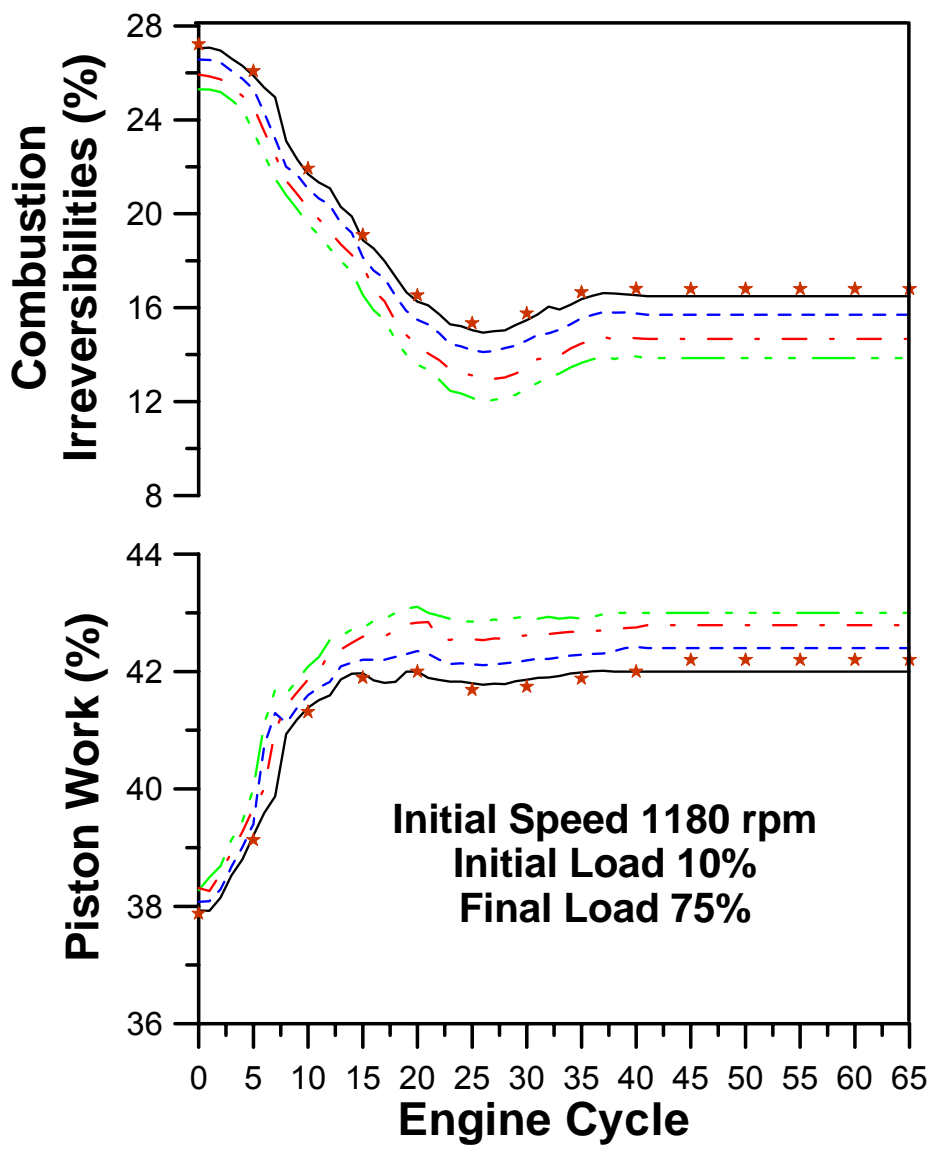

$$
A_{\text {out }}=\int_{0}^{720} \frac{d m_{7}}{d \varphi} b_{7} d \varphi
$$

\section{RESULTS AND DISCUSSION}

Figure 13 focuses on the second-law balance and illustrates the evolution of four basic engine availability values during the transient event, i.e. piston work, heat loss to the cylinder walls, exhaust gas to ambient, and combustion irreversibilities; they are all reduced to the fuel chemical availability. The important finding here is that an increasing degree of insulation proves favorable from the second-law perspective, since the corresponding combustion irreversibilities decrease as a percentage or even as absolute values. This happens due to the fact that an increasing (due to insulation) wall temperature increases the charge temperatures and, consequently, as the ideal cycle of Carnot suggests, lowers the degradation of the fuel availability since the fuel's chemical exergy is now transferred to 'hotter' gases. For example, for the $1.5 \mathrm{~mm}$ PSZ case, the combustion irreversibilities decrease up to $23.5 \%$ compared to the non-insulated configuration, which is indeed a considerable gain. This finding expands on the steady-state results of previous researchers [12-16].

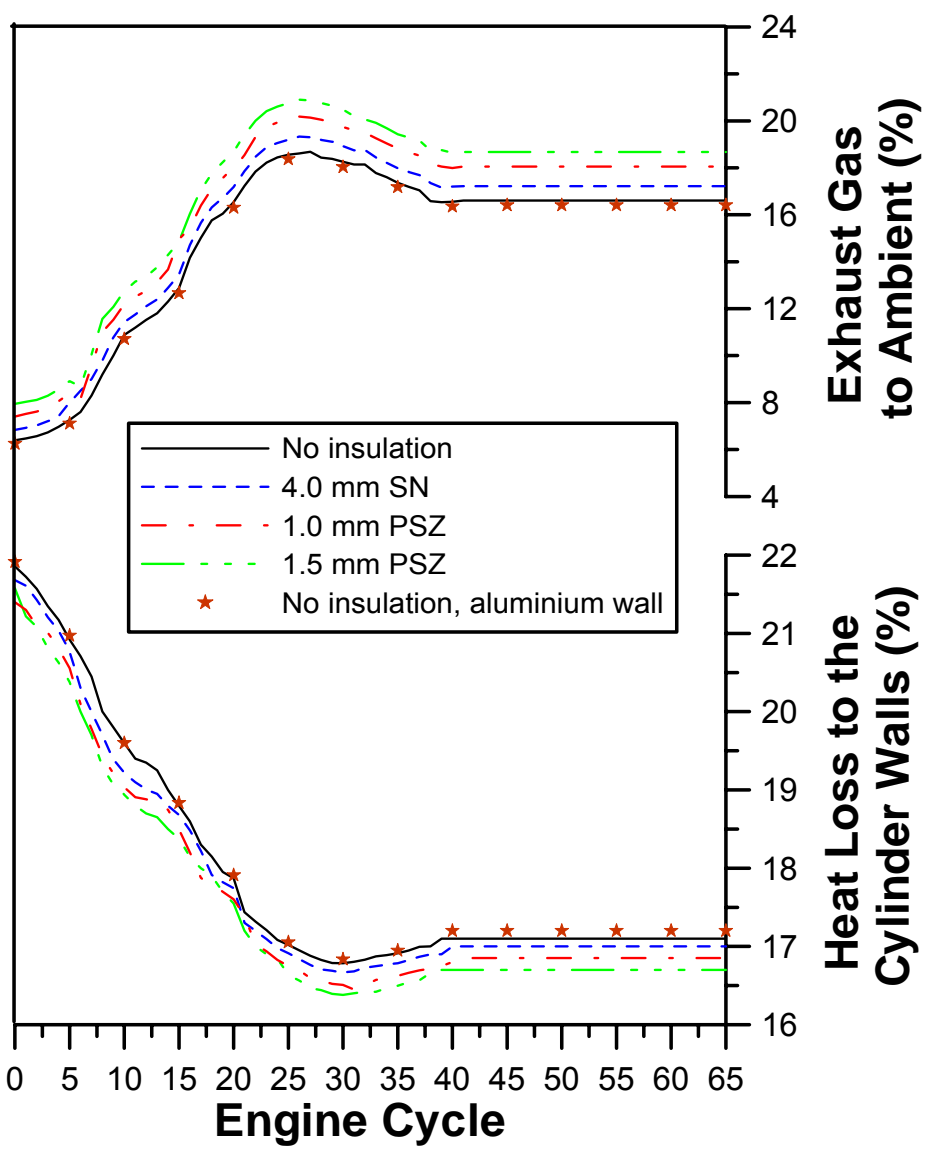

Fig. 13. Response of various second-law values to an increase in load (unless otherwise noted, the cylinder wall is cast iron) 
It should be emphasized here that the combustion irreversibilities during transients evolve in a different way compared to the respective steady-state operation (i.e. for the same engine speed and fuel pump rack position). In Fig. 14 a comparison is illustrated between transient and some intermediate 'steady-state' in-cylinder irreversibility values (i.e. steady-state irreversibilities for the same engine speed and fuel pump rack position of the corresponding transient cycles). The work by Van Gerpen and Shapiro [45] revealed that during steadystate operation the effect of both combustion duration and shape of heat release curve is modest as regards the total amount of irreversibilities, although the rate of irreversibility production is greatly affected. An attempt to directly expand this finding into the transient operation regime would result in the misleading assumption that transient cumulative combustion irreversibilities per cycle should practically be affected only by the amount of injected fuel (established from the respective steadystate fuel pump curves through the values of fuel pump rack position and engine speed). However, during transients various off-design phenomena occur mainly during the early cycles, e.g., a) influence in mixture formation and ignition delay due to air-deficiency caused by turbocharger lag, b) change in the average fuel droplet diameter caused by lower density and swirl, which leads to increased jet penetration in comparison to the respective steady-state operating conditions, c) lower end gas and wall temperatures in combination with a higher amount of end gas resulting in an increased ignition delay and hard combustion course, during the early cycles where the turbocharger lag is more prominent [20].

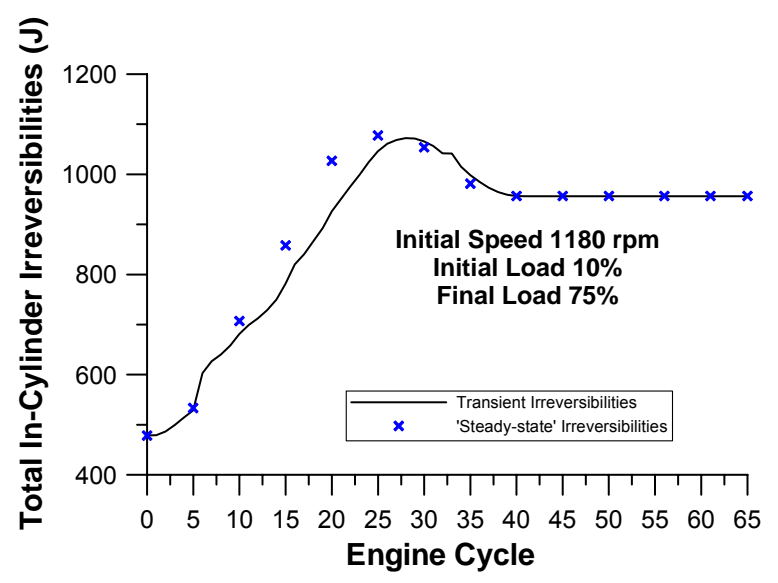

Fig. 14. Comparison between total engine irreversibilities (reduced to one engine cylinder) with intermediate 'steady-state' irreversibilities, during a load increase

In Figure 14, a difference up to $11 \%$ at the 20th cycle this is indeed an 'early' cycle of the transient event, as the particular engine-brake configuration has a very large value of mass moment of inertia- is observed when comparing the transient with the respective 'steadystate' irreversibilities. This illustrates, in an explicit way, the different evolution profile of the transient combustion irreversibilities compared to steady-state operation. The difference is attributed to:

- the differentiated fuel-air equivalence ratios experienced during transients owing to the turbocharger lag, which significantly affects the airmass flow rate,

- the transient operation of the fuel pump that differentiates from the steady-state fuel pump curves [21], and

- the fact that, during transients, integration of the left hand side of Eq. (16) over an engine cycle does not sum up to zero, as the initial conditions of the new cycle differ from the initial conditions of the previous one.

Ideally, a $23.5 \%$ reduction in combustion irreversibilities would form a sound basis for a remarkable increase in engine efficiency. Unfortunately, although the combustion proceeded in a more efficient way, this was not transformed into increased piston work (Fig. 13, lower left sub-diagram). Hence, the work term is only marginally improved $(+2.3 \%$ at cycle No. 25 of the 1.5 $\mathrm{mm}$ PSZ case). This finding goes along with the (firstlaw) isfc results depicted in Fig. 9, and with the conclusions reached by previous researchers for steadystate operation [12,13]. The reduction in combustion irreversibilities was rather reflected into an increase in the exhaust gas to ambient exergy. Both the absolute (in 'Joules') and percentage values of this term increased with higher degree of insulation, owing to the higher temperature of the working medium (see also Table 4). This availability amount could be afterwards recovered only if a bottoming cycle is applied, which for the present investigation would be a Rankine cycle; the use of a turbo-compound device is not recommended owing to the low pressure ratios involved.

Table 4. Max. increase (at a particular cycle) in second-law values for the engine with $1.5 \mathrm{~mm}$ PSZ coating compared to the non-insulated operation

\begin{tabular}{|c|c|}
\hline Work & $+2.3 \%$ \\
\hline Combustion irreversibilities & $-23 \%$ \\
\hline Total irreversibilities & $-19 \%$ \\
\hline Heat loss to the walls & $-1.5 \%$ \\
\hline Exhaust gas to ambient & $+15 \%$ \\
\hline
\end{tabular}

On the other hand, a higher degree of insulation slightly decreases the exergy of heat loss to the cylinder walls when reduced to the fuel chemical availability. Eq. (18) shows that an increasing gas temperature $T_{g}$ (depicted in Fig. 15 for an intermediate cycle of the transient 
event) increases the 'quality' and thus the amount of heat transfer availability.

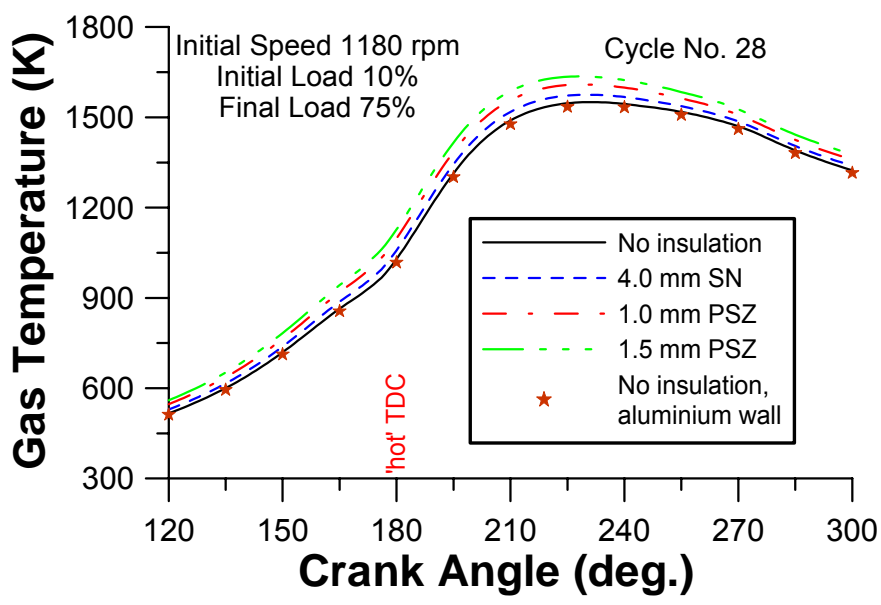

Fig. 15. Gas temperature variation during cycle No 28 of the $10-75 \%$ transient event

This is contradicted by the fact that a higher insulation scheme reduces the heat flux $d Q_{L} / d \varphi$ to the cylinder walls (Fig. 7). The combined effect of the above factors determines the trend for the percentage exergy term of heat loss depicted in Fig. 13. However, it should be highlighted that this exergy term of heat loss to the walls possesses now a higher work potential as the wall temperature has increased with insulation. A heat recovery device is needed in order for this availability to be exploited. At the moment, the subsequent heat transfer to the cooling medium practically causes its elimination.

Figure 16 illustrates the response of the percentage combustion irreversibilities -i.e. combustion irreversibilities reduced to the total engine and subsystems irreversibilities- during the transient event. Again, the higher the degree of insulation the lower the percentage of combustion irreversibilities, with this trend enhanced by higher loading. It is interesting to note that even the absolute values (in 'Joules") of the combustion irreversibilities decrease with higher insulations. At the same time, other irreversibility terms such as exhaust manifold (depicted for the $1.0 \mathrm{~mm}$ PSZ coating in Fig. 16 ) or turbine ones were found to increase.

This rather conflicting behavior can be explained if one looks deeper into the respective irreversibility production mechanisms. For the combustion term, the main mechanism comprises the heat transfer from the burning of fuel to the gases. Consequently, the higher the temperature of the receiving gas (as is the case with increasing insulation) the lower the degradation of the fuel's chemical exergy, and hence the combustion irreversibilities. On the other hand, turbocharger aftercooler, inlet manifold and exhaust manifold irreversibilities are attributed to throttling, mixing and friction. These depend mainly on the level of pressures and temperatures of the working medium; thus, they increase with higher insulations.

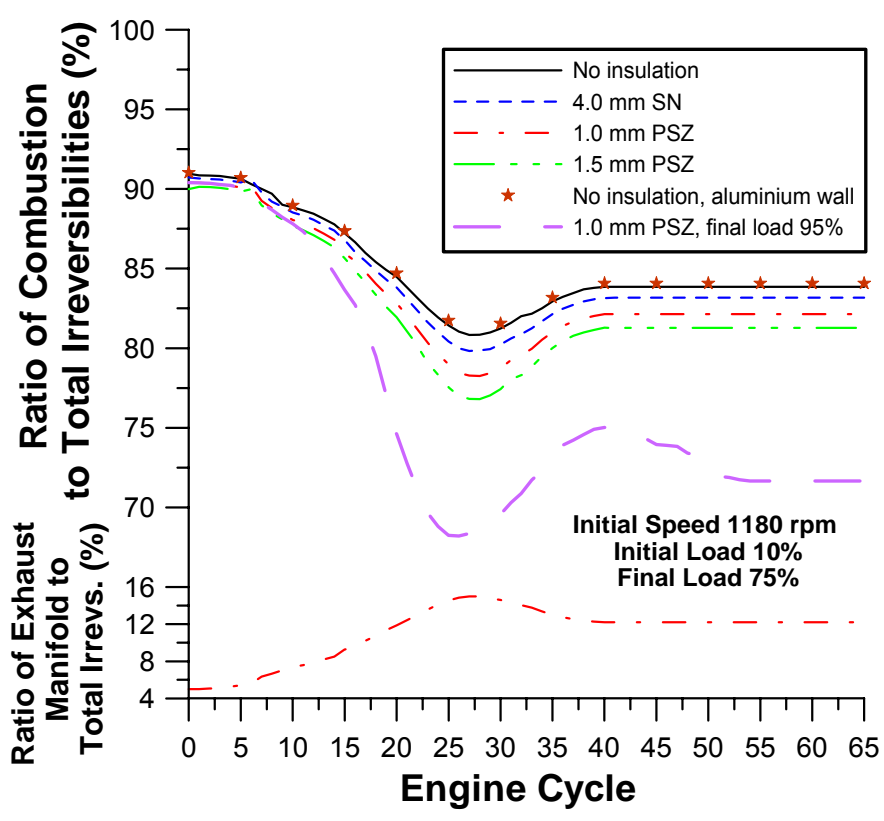

Fig. 16. Response of percentage combustion irreversibilities to an increase in load (unless otherwise noted, the cylinder wall is cast iron and the load-increase is $10-75 \%$ )

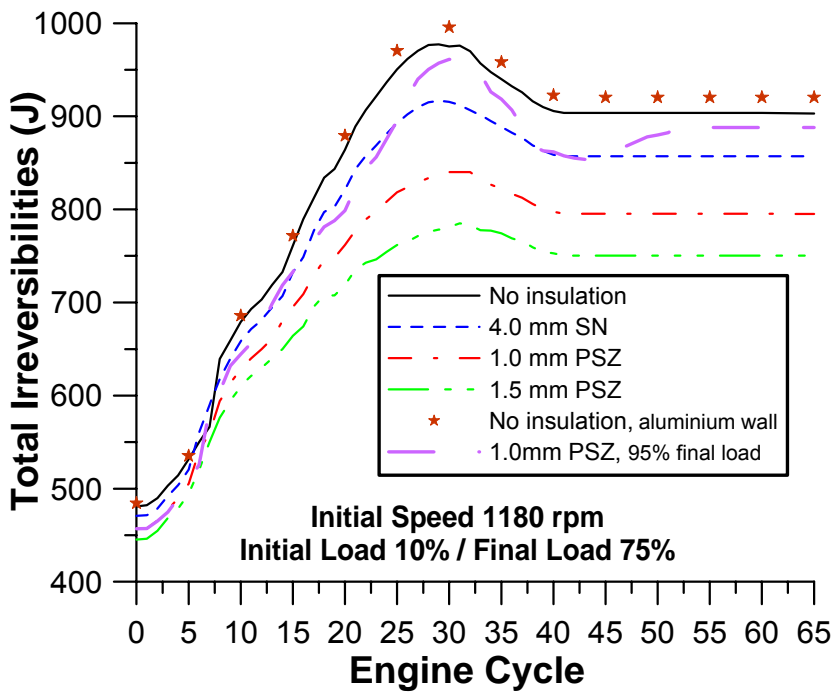

Fig. 17. Response of total engine irreversibilities (reduced to one cylinder) to an increase in load (unless otherwise noted, the cylinder wall is cast iron and the load-increase is $10-75 \%$ )

Again, the case with aluminium wall only slightly differentiates from the cast iron one. In any case, it is important to note that the higher amount of exhaust manifold and turbine irreversibilities, especially under 
high loading, are always of much lesser importance throughout the whole transient event. As a result, even the absolute amount of the total engine irreversibilities (in 'Joules') decreases considerably (up to 19.5\%) with higher insulation, as it is illustrated in Fig. 17 and quantified in Table 4.

Finally, Figs 18 and 19 quantify the gain obtained from insulation during the transient event from the second-law perspective.

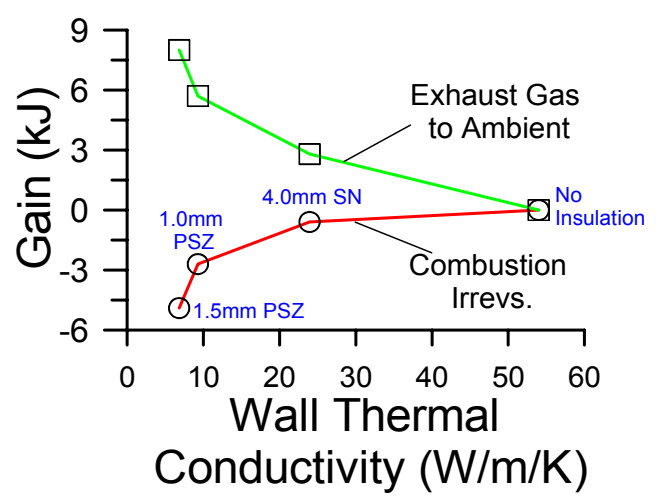

Fig. 18. Gain from insulation compared to the non-insulated operation during the whole transient event

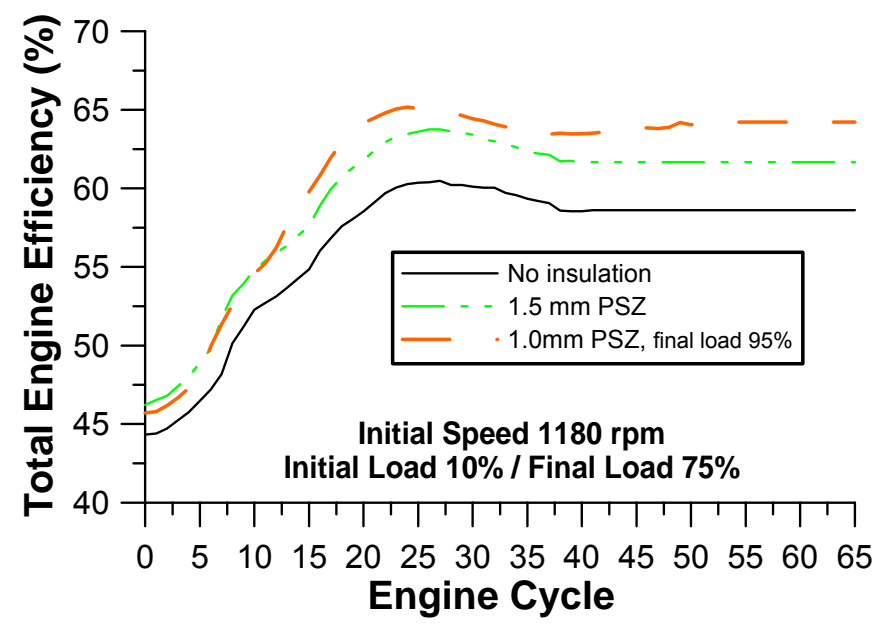

Fig. 19. Response of total (=work + exhaust gas to ambient) engine efficiency to an increase in load (unless otherwise noted the loadincrease is $10-75 \%$ )

Fig. 18 illustrates the total gain from the insulation as regards two important second-law values, i.e. combustion irreversibilities (defined as 'theoretical' gain) and exhaust gas to ambient exergy (defined as 'practical' gain), during the whole transient event. The gain in the work potential of the exhaust gas to ambient reaches $8 \mathrm{~kJ}$ or $2 \mathrm{~kW}$ during the $4 \mathrm{~s}$ of the transient event, for the $1.5 \mathrm{~mm}$ PSZ coating compared to the noninsulated operation. This would correspond to a $2.4 \%$ increase in the engine brake power. This is the maximum extra power that can be obtained during the transient event from the increased insulation if a bottoming cycle is applied. The respective engine efficiency from Eq. (20) -taking into account both indicated work and exhaust gas to ambient exergy- is plotted in Fig. 19. Here, it is made obvious that in work's terms the gain from the insulation increases the engine's efficiency by almost $6.5 \% \quad(1.5 \mathrm{~mm}$ PSZ coating compared to the non-insulated operation). Any thoughts to further exploit this extra amount of work potential must be realized, taking into account the following:

1. The respective steady-state gains (that, hopefully, go along with the transient results [12]), and

2. The financial burden induced from the more complicated engine configuration.

\section{CONCLUSIONS}

An experimentally validated thermodynamic model was used to study the transient performance of a low heat rejection turbocharged diesel engine. The model is used to investigate the effect of engine wall materials of special technological importance, such as the wellknown insulators silicon nitride or plasma spray zirconia, on the values of engine performance and cyclic temperature swings during transients. For the present engine-load configuration the analysis revealed the following:

- An increased degree of insulation during a typical transient load increase, of the order of $10-75 \%$, resulted in increased gas and wall temperatures, heat transfer coefficients and, mainly, amplitude of temperature swings and temperature gradients. The latter may take prohibitive values causing severe wall thermal fatigue, so that proper care should be taken as regards the thermal stress of the engine components.

- The transient response of the engine exhibits a behavior that goes along with the respective steadystate performance. Namely, the higher temperature levels observed throughout the cycle result in decreased volumetric efficiency and slightly improved indicated efficiency. The main finding for the particular engine-load setup was the rather unaffected, by the level of applied insulation, response of all engine and turbocharger non-heattransfer-related values, with the latter attributed to the high moment of inertia of the current engine-load configuration.

- No significant distinction was noticed between cast iron and aluminium wall as regards engine response.

- The second-law balance results are much more coherent than their first-law counterparts. Secondlaw values were found to depend strongly on the applied insulation scheme. The dominant combustion irreversibilities decreased considerably with higher degree of insulation both in 'Joules' and 
as a percentage of either fuel availability (up to $23.5 \%$ at a certain cycle, when comparing the 1.5 $\mathrm{mm}$ PSZ coating to the non-insulated case) or total irreversibilities.

- Unfortunately, this decrease in the availability destruction could not be recovered as an increase in piston work; it was mainly transformed into an increase in the availability content of the exhaust gas to ambient. The corresponding amount was $8 \mathrm{~kJ}$ or $2 \mathrm{~kW}$ for the $1.5 \mathrm{~mm}$ PSZ coating compared to the non-insulated operation, which, if fully transformed into work via a bottoming cycle, could contribute a $2.4 \%$ increase in engine brake power. Consequently, up to $6.5 \%$ increase in the engine's second-law efficiency can be achieved.

The insight gained from this study as regards first- vs. second-law balance results, is believed to provide a sound basis for an alternative view of internal combustion engines thermodynamic processes possibly to be applied in future works.

\section{REFERENCES}

1. Annand, W. J. D. and Ma, T. H., 'Instantaneous Heat Transfer Rates to the Cylinder Head Surface of a Small Compression-Ignition Engine'. Proceedings of the Institution of Mechanical Engineers, Vol. 185, pp. 976-987, 1970-71.

2. Assanis, D.N. and Heywood, J.B., 'Development and Use of a Computer Simulation of the TurboCompounded Diesel Engine Performance and Component Heat Transfer Studies', SAE Paper No. 860329, 1986.

3. Borman, G. and Nishiwaki, K., 'Internal-Combustion Engine Heat Transfer', Progress in Energy and Combustion Science, Vol. 13, pp. 1-46, 1987.

4. Benson, R.S. and Whitehouse, N.D., Internal Combustion Engines, Pergamon Press, Oxford, 1979.

5. Heywood, J.B., Internal Combustion Engine Fundamentals, McGraw-Hill, New York, 1988.

6. Bryzik, W. and Kamo, R., 'Tacom/Cummins Adiabatic Engine Program', SAE Paper No. 830314, 1983.

7. Jennings, M.J. and Morel, T., 'A Computational Study of Wall Temperature Effects on Engine Heat Transfer', SAE Paper No. 910459, 1991.

8. Alkidas, A.C., 'Performance and Emissions Achievements with an Uncooled Heavy-Duty, Single-Cylinder Diesel Engine', SAE Paper No. 890144, 1989.

9. Assanis, D., Wiese, K., Schwartz, E. and Bryzik, W., 'The Effects of Ceramic Coatings on Diesel Engine Performance and Exhaust Emissions', SAE Paper No. 910460, 1991.

10. Wong, V.W., Bauer, W., Kamo, R., Bryzik, W. and Reid, M., 'Assessment of Thin Thermal Barrier Coatings for I.C. Engines', SAE Paper No. 950980, 1995.
11. Rakopoulos, C.D. and Mavropoulos, G.C.,' Modeling the Transient Heat Transfer in the Ceramic Combustion Chamber Walls of a Low Heat Rejection Diesel Engine', International Journal of Vehicle Design, Vol. 22, pp. 195-215, 1999.

12. Rakopoulos, C.D. and Giakoumis, E.G., 'SecondLaw Analyses Applied to Internal Combustion Engine Operation', Progress in Energy and Combustion Science, Vol. 32, pp. 2-47, 2006.

13. Alkidas, A.C., 'The Application of Availability and Energy Balances to a Diesel Engine', ASME Transactions, Journal of Engineering for Gas Turbines and Power, Vol. 110, pp. 462-469, 1988.

14. Caton, J.A., 'On the Destruction of Availability (Exergy) due to Combustion Processes - with Specific Application to Internal-Combustion Engines', Energy, Vol. 25, pp. 1097-1117, 2000.

15. Flynn, P.F., Hoag, K.L., Kamel, M.M. and Primus, R.J., 'A New Perspective on Diesel Engine Evaluation Based on Second Law Analysis', SAE Paper No. 840032, 1984.

16. Primus, R.J., Hoag, K.L., Flynn, P.F. and Brands, M.C., 'An Appraisal of Advanced Engine Concepts Using Second Law Analysis Techniques', SAE Paper No. 841287, 1984.

17. Watson, N., 'Dynamic Turbocharged Diesel Engine Simulator for Electronic Control System Development', ASME Transactions, Journal of Dynamic Systems, Measurement and Control, Vol. 106, pp. 27-45, 1984.

18. Winterbone, D.E., 'Transient Performance', in J.H. Horlock and D.E. Winterbone (eds.) The Thermodynamics and Gas Dynamics of Internal Combustion Engines, Vol. II, Clarendon Press, Oxford, 1986.

19. Rakopoulos, C.D., Giakoumis, E.G., Hountalas, D.T. and Rakopoulos, D.C., 'The Effect of Various Dynamic, Thermodynamic and Design Parameters on the Performance of a Turbocharged Diesel Engine Operating under Transient Load Conditions', SAE Paper No. 2004-01-0926, 2004.

20. Rakopoulos, C.D. and Giakoumis, E.G., 'Review of Thermodynamic Diesel Engine Simulations under Transient Operating Conditions', SAE Paper No. 2006-01-0884, 2006.

21. Rakopoulos, C.D. and Giakoumis, E.G., 'Sensitivity Analysis of Transient Diesel Engine Simulation', Proceedings of the Institution of Mechanical Engineers, Part D, Journal of Automobile Engineering, Vol. 220, pp. 89-101, 2006.

22. Keribar, R. and Morel, T., 'Thermal Shock Calculations in I.C. Engines', SAE Paper No. 870162, 1987.

23. Schorn, N., Pischinger, F. and Schulte, H., 'Computer Simulation of Turbocharged Diesel Engines under Transient Conditions', SAE Paper No. 870723, 1987.

24. Rakopoulos, C.D., Hountalas, D.T., Mavropoulos, G.C. and Giakoumis, E.G., 'An Integrated Transient Analysis Simulation Model Applied in Thermal 
Loading Calculations of an Air-Cooled Diesel Engine under Variable Speed and Load Conditions', SAE Paper No. 970634, 1997. Also in SAE Transactions, Journal of Engines, Vol. 106, pp. 923-939, 1997.

25. Rakopoulos, C.D., Hountalas, D.T. and Mavropoulos, G.C., 'Modeling the Structural Thermal Response of an Air-Cooled Diesel Engine under Transient Operation Including a Detailed Thermodynamic Description of Boundary Conditions', SAE Paper No. 981024, 1998.

26. Rakopoulos, C.D., Antonopoulos, K.A., Rakopoulos, D.C. and Giakoumis, E.G., 'Investigation of the Temperature Oscillations in the Cylinder Walls of a Diesel Engine with Special Reference to the Limited Cooled Case', International Journal of Energy Research, Vol. 28, pp. 977-1002, 2004.

27. Rakopoulos, C.D., Rakopoulos, D.C., Mavropoulos, G.C. and Giakoumis, E.G., 'Experimental and Theoretical Study of the Short Term Response Temperature Transients in the Cylinder Walls of a Diesel Engine at Various Operating Conditions', Applied Thermal Engineering, Vol. 24, pp. 679-702, 2004.

28. Yamada, Y., Emi, M., Ishii, H., Suzuki, Y., Kimura, S. and Enomoto, Y., 'Heat Loss to the Combustion Chamber Wall with Deposit in D.I. Diesel Engine: Variation of Instantaneous Heat Flux on Piston Surface with Deposit', JSAE Review, Vol. 23, pp. 415-421, 2002.

29. Alkidas, A.C. and Myers, J.P., 'Transient Heat-Flux Measurements in the Combustion Chamber of a Spark-Ignition Engine', ASME Transactions, Journal of Heat Transfer, Vol. 104, pp. 62-67, 1982.

30. Alkidas, A.C. and Cole, R.M., 'Transient Heat-Flux Measurements in a Divided-Chamber Diesel Engine', ASME Transactions, Journal of Heat Transfer, Vol. 107, pp. 439-444, 1985.

31. Rakopoulos, C.D. and Mavropoulos, G.C., 'Experimental Instantaneous Heat Fluxes in the Cylinder Head and Exhaust Manifold of an AirCooled Diesel Engine', Energy Conversion and Management, Vol. 41, pp. 1265-1281, 2000.

32. Whitehouse, N.D. and Way, R.G.B., 'Rate of Heat Release In Diesel Engines and its Correlation with Fuel Injection Data', Proceedings of the Institution of Mechanical Engineers, Part 3J, Vol. 184, pp. 17-27, 1969-70.

33. Gebhart, B., Heat Transfer, McGraw-Hill, New York, 1971.

34. Myers, G.E., Analytical Methods in Conduction Heat Transfer, McGraw-Hill, New York, 1971.

35. Eckert, E.R.G. and Drake, R.M. Jr., Heat and Mass Transfer ( $2^{\text {nd }}$ edn), McGraw-Hill, New York, 1959.

36. Churchill, R.V., Fourier Series and Boundary Value Problems, McGraw-Hill, New York, 1963.

37. Rakopoulos, C.D. and Hountalas, D.T., 'A Simulation Analysis of a DI Diesel Engine Fuel Injection System Fitted with a Constant Pressure Valve', Energy Conversion and Management, Vol. 37, pp. 135-150, 1996.
38. Taraza, D., Henein, N. and Bryzik, W., 'Friction Losses in Multi-Cylinder Diesel Engines', SAE Paper No. 2000-01-0921, 2000.

39. Stanley, R., Taraza, D., Henein, N. and Bryzik, W., 'A Simplified Model of the Piston Ring Assembly', SAE Paper No. 1999-01-0974, 1999.

40. Scwartz, E., Reid, M., Bryzik, W. and Danielson, E., 'Combustion and Performance Characteristics of a Low Heat Rejection Engine', SAE Paper No. 930988, 1993.

41. Alkidas, A.C., 'The Use of Availability and Energy Balances in Diesel Engines', SAE Paper No. 890822, 1989.

42. Rakopoulos, C.D., Andritsakis, E.C. and Kyritsis, D.C., 'Availability Accumulation and Destruction in a DI Diesel Engine with Special Reference to the Limited Cooled Case', Heat Recovery Systems and CHP, Vol. 13, pp. 261-276, 1993.

43. Rakopoulos, C.D. and Giakoumis, E.G., 'Availability Analysis of a Turbocharged Diesel Engine Operating under Transient Load Conditions', Energy, Vol. 29, pp. 1085-1104, 2004.

44. Rakopoulos C.D. and Giakoumis E.G., 'Parametric Study of Transient Turbocharged Diesel Engine Operation from the Second-Law Perspective', SAE Paper No. 2004-01-1679, 2004.

45. Van Gerpen, J.H. and Shapiro, H.N., 'Second-Law Analysis of Diesel Engine Combustion', ASME Transactions, Journal of Engineering for Gas Turbines and Power, Vol. 112, pp. 129-137, 1990.

\section{CONTACT}

Professor C.D. Rakopoulos (cdrakops@central.ntua.gr) and Dr. E.G. Giakoumis (vgiakms@central.ntua.gr): National Technical University of Athens (NTUA), School of Mechanical Engineering, Thermal Engineering Department, 9 Heroon Politechniou St., Zografou Campus, 15780, Athens, Greece.

\section{DEFINITIONS, ACRONYMS, ABBREVIATIONS}

A Availability (exergy), $\mathrm{J}$

b Flow availability (flow exergy), $\mathrm{J} / \mathrm{kg}$

D Cylinder bore, $\mathrm{m}$

$\mathrm{F} \quad$ Surface area, $\mathrm{m}^{2}$

$\mathrm{G} \quad$ Moment of inertia, $\mathrm{kg} \mathrm{m}^{2}$

h Specific enthalpy, J/kg, or Heat transfer coefficient, $\mathrm{W} / \mathrm{m}^{2} \mathrm{~K}$

I Irreversibilities, J

k Thermal conductivity, $\mathrm{W} / \mathrm{m} \mathrm{K}$

L Thickness, $\mathrm{mm}$

$\dot{\mathrm{m}} \quad$ Mass flow, $\mathrm{kg} / \mathrm{s}$

$\mathrm{M}$ Torque, $\mathrm{Nm}$

$\mathrm{N} \quad$ Engine speed, rpm

$\mathrm{p}$ Pressure, bar

Q Heat, J

$r \quad$ Pressure or expansion ratio

S Specific entropy, $\mathrm{J} / \mathrm{kg} \mathrm{K}$

$\mathrm{T} \quad$ Temperature, $\mathrm{K}$ 
$\mathrm{t} \quad$ Time, $\mathrm{s}$

$\mathrm{V} \quad$ Volume, $\mathrm{m}^{3}$

Greek letters

a Thermal diffusivity, $\mathrm{m}^{2} / \mathrm{s}$

$\eta \quad$ Efficiency, \%

$\mu \quad$ Chemical potential, J/kg

T Time period, $\mathrm{s}$

$\varphi \quad$ Crank angle, deg

$\Phi$ Fuel-air equivalence ratio

$\omega \quad$ Angular velocity, $\mathrm{rad} / \mathrm{s}$

\section{Subscripts}

o Initial/atmospheric conditions

c Coolant

C Compressor

e Engine

f Fuel

g Gas

i Injected

in/ex Inlet/Exhaust

ins Insulation

is Isentropic

L Loss

p Time Periodic

$T \quad$ Turbine

TC Turbocharger

w Wall, or Work

Abbreviations

${ }^{\circ} \mathrm{CA}$ Degrees of crank angle

bmep Brake mean effective pressure, bar

isfc Indicated specific fuel consumption, $\mathrm{g} / \mathrm{kWh}$

LHR Low heat rejection

LVDT Linear variable displacement transducer

MUX Multiplexer unit

PSZ Plasma spray zirconia

rpm Revolutions per minute

SMD Sauter mean diameter, $\mu \mathrm{m}$

SN Silicon nitride

Sol Start of Injection

TDC Top dead center 